\title{
A revised biosynthetic pathway for the cofactor $\mathbf{F}_{420}$ in bacteria
}

Ghader Bashiri $^{* \#}$, James Antoney ${ }^{2,3 \#}$, Ehab N. M. Jirgis ${ }^{1}$, Mihir V. Shah ${ }^{2}$, Blair Ney ${ }^{2,3}$, Janine Copp ${ }^{4}$, Stephanie M. Stutely ${ }^{1}$, Sreevalsan Sreebhavan ${ }^{5}$, Brian Palmer ${ }^{5}$, Martin Middleditch $^{1}$, Nobuhiko Tokuriki ${ }^{4}$, Chris Greening ${ }^{2,6}$, Edward N. Baker ${ }^{1}$, Colin Scott ${ }^{2 *}$, Colin J. Jackson $^{2,3 *}$

${ }^{1}$ School of Biological Sciences and Maurice Wilkins Centre for Molecular Biodiscovery, The University of Auckland, Auckland 1010, New Zealand

${ }^{2}$ Synthetic Biology Future Science Platform, CSIRO Land \& Water, Canberra, ACT, Australia

${ }^{3}$ Research School of Chemistry, Australian National University, Acton, Australian Capital Territory, Australia

${ }^{4}$ Michael Smith Laboratories, University of British Columbia, Vancouver, BC, V6T 1Z4, Canada.

${ }^{5}$ Auckland Cancer Society Research Centre, Faculty of Medical and Health Sciences, The University of Auckland, Auckland 1010, New Zealand

${ }^{6}$ School of Biological Sciences, Monash University, Clayton, Victoria, Australia

\# These authors contributed equally to this work.

* Corresponding author contact details: Ghader Bashiri

Phone: +64-9-9235791

Email: g.bashiri@auckland.ac.nz

Colin Jackson

Phone: +61-2-61258325

Email: colin.jackson@anu.edu.au

Colin Scott

Phone: +61262464090

Email: colin.scott@csiro.au

Keywords: Cofactor $\mathrm{F}_{420}$, actinomycetes, mycobacteria, biosynthesis, methanogens, 2-phospho-L-lactate, phosphoenolpyruvate 


\begin{abstract}
Cofactor $\mathrm{F}_{420}$ plays critical roles in primary and secondary metabolism in a range of bacteria and archaea as a low-potential hydride transfer agent. It mediates a variety of important redox transformations involved in bacterial persistence, antibiotic biosynthesis, pro-drug activation and methanogenesis. However, the biosynthetic pathway for $\mathrm{F}_{420}$ has not been fully elucidated: neither the enzyme that generates the putative intermediate 2-phospho- $L$-lactate, nor the function of the FMN-binding C-terminal domain of the $\gamma$-glutamyl ligase (FbiB) in bacteria are known. Here we show that the guanylyltransferases FbiD and CofC accept phosphoenolpyruvate, rather than 2-phospho- $L$-lactate, as their substrate, leading to the formation of the previously uncharacterized intermediate, dehydro-F420-0. The C-terminal domain of FbiB then utilizes $\mathrm{FMNH}_{2}$ to reduce dehydro- $\mathrm{F}_{420}-0$, which produces mature $\mathrm{F}_{420}$ species when combined with the $\gamma$-glutamyl ligase activity of the $\mathrm{N}$-terminal domain. This new insight has allowed the heterologous expression $\mathrm{F}_{420}$ from a recombinant $\mathrm{F}_{420}$ biosynthetic pathway in Escherichia coli.
\end{abstract}


Cofactor $\mathrm{F}_{420}$ is a deazaflavin that acts as a hydride carrier in diverse redox reactions in both bacteria and archaea ${ }^{1,2}$. While $\mathrm{F}_{420}$ structurally resembles the flavins FMN and FAD, it functions as an obligate two-electron hydride carrier and hence is functionally analogous to the nicotinamides $\mathrm{NAD}^{+}$and $\mathrm{NADP}^{+3}$. The lower reduction potential of the $\mathrm{F}_{420}$, relative to the flavins, results from the substitution of N5 of the isoalloxazine ring in the flavins for a carbon in $\mathrm{F}_{420}{ }^{4,5}$. Originally characterized from methanogenic archaea in $1972^{4,5}, \mathrm{~F}_{420}$ is an important catabolic cofactor in methanogens and mediates key one-carbon transformations of methanogenesis $^{6} . F_{420}$ has since been shown to be synthesized in a range of archaea and bacteria ${ }^{1,2,7,8}$. In Mycobacterium tuberculosis, the causative agent of tuberculosis, $\mathrm{F}_{420}$ has been shown to contribute to persistence ${ }^{9,10}$ and to activate the new clinical antitubercular prodrugs delamanid and pretomanid ${ }^{11}$. There are also growing numbers of natural products that have been shown to be synthesized through $\mathrm{F}_{420}$-dependent pathways, including tetracyclines ${ }^{12}$, lincosamides ${ }^{13}$, and thiopeptides ${ }^{14}$. $\mathrm{F}_{420}$-dependent enzymes have also been explored for bioremediation and biocatalytic applications ${ }^{15,16}$.

The currently accepted $\mathrm{F}_{420}$ biosynthetic pathway consists of two branches ${ }^{2}$. In the first branch, tyrosine is condensed with 5-amino-6-ribitylamino-2,4[1H,3H]-pyrimidinedione from the flavin biosynthetic pathway to generate the deazaflavin chromophore Fo (7,8-didemethyl-8-hydroxy-5-deazariboflavin) via the activity of the two-domain Fo synthase FbiC, or the CofG/H pair (where 'Fbi' refers to mycobacterial proteins and 'Cof' refers to archaeal homologs). In the second branch, it has been hypothesized that a 2-phospho- $L$-lactate guanylyltransferase (CofC in archaea and the putative enzyme FbiD in bacteria) catalyzes the guanylylation of 2-phospho-L-lactate (2-PL) using guanosine-5'-triphosphate (GTP), yielding $L$-lactyl-2-diphospho-5'-guanosine (LPPG) ${ }^{17}$. The two branches then merge at the reaction 
catalyzed by the transferase FbiA/CofD, where the 2-phospho- $L$-lactyl moiety of LPPG is transferred to Fo, forming $\mathrm{F}_{420^{-}} 0^{18,19}$. Finally, the $\gamma$-glutamyl ligase (FbiB/CofE) catalyzes the poly-glutamylation of $\mathrm{F}_{420}$ to generate mature $\mathrm{F}_{420}$, with poly- $\gamma$-glutamate tail lengths of $\sim 2-8$, depending on species ${ }^{20,21}$.

There are three aspects of the $\mathrm{F}_{420}$ biosynthetic pathway that require clarification. First, the metabolic origin of 2-PL, the proposed substrate for CofC, is unclear. It has been assumed that a hypothetical kinase (designated CofB) phosphorylates $L$-lactate to produce 2$\mathrm{PL}^{22}$. However, no such enzyme for the production of 2-PL has been identified in bacteria or archaea, and our genomic analysis of $\mathrm{F}_{420}$ biosynthesis operons has failed to identify any candidate enzymes with putative $L$-lactate kinase activity ${ }^{2}$. Second, the existence of FbiD has only been inferred through bioinformatics and genetic knockout studies and the enzyme has not been formally characterized ${ }^{23,24}$. Finally, the bacterial $\gamma$-glutamyl ligase FbiB is a two-domain protein ${ }^{20}$, in which the N-terminal domain is homologous to other $\mathrm{F}_{420}-\gamma$-glutamyl ligases (including the archaeal equivalent, CofE) and the C-terminal domain adopts an FMNbinding nitroreductase (NTR) fold ${ }^{20}$. Although both domains are required for full $\gamma$-glutamyl ligase activity, no function has been associated with either the C-terminal domain or the FMN cofactor, given no redox reactions are known to be involved in $\mathrm{F}_{420}$ biosynthesis.

Here we demonstrate that 2-PL is not required for $\mathrm{F}_{420}$ biosynthesis in bacteria and instead phosphoenolpyruvate (PEP), an abundant intermediate of glycolysis and gluconeogenesis, is incorporated into $\mathrm{F}_{420}$. We show that PEP guanylylation is catalyzed by the CofC and FbiD enzymes that were previously thought to act upon 2-PL. In bacteria, the incorporation of 
PEP in the pathway results in the production of the previously undetected intermediate dehydro- $\mathrm{F}_{420}-0$, which is then reduced by the $\mathrm{C}$-terminal domain of FbiB alongside poly-glutamylation. These findings result in a substantially revised pathway for $\mathrm{F}_{420}$ biosynthesis and have allowed us to heterologously produce functional $\mathrm{F}_{420}$ in engineered Escherichia coli, an organism that does not normally produce $\mathrm{F}_{420}$, at levels comparable to some native $\mathrm{F}_{420 \text {-pro- }}$ ducing organisms.

\section{Results}

\section{FbiD/CofC use phosphoenolpyruvate, rather than 2-phospho- $L$-lactate, as a substrate}

The archaeal enzyme CofC has previously been suggested to catalyze the guanylylation of 2PL to produce LPPG during $\mathrm{F}_{420}$ biosynthesis (Fig. 1a) ${ }^{25}$. Another study, using transposon mutagenesis, has shown that MSMEG_2392 of Mycobacterium smegmatis is essential in the biosynthesis of $\mathrm{F}_{420}$ from $\mathrm{Fo}^{23}$. We have recently shown that homologs of this gene have sequence homology to CofC and belong to operons with other validated $\mathrm{F}_{420}$ biosynthetic genes in a wide variety of bacteria $^{2}$. In keeping with the bacterial naming system, we refer to this enzyme as FbiD. To test the function of this putative bacterial FbiD, we cloned the Rv2983 gene from $M$. tuberculosis $^{26}$ into a mycobacterial expression vector and purified heterologously expressed Mtb-FbiD from $M$. smegmatis $\mathrm{mc}^{2} 4517$ host cells. We also expressed and purified $M t b$-FbiA (the enzyme thought to transfer the 2-phospho- $L$-lactyl moiety of LPPG to Fo to produce $\left.\mathrm{F}_{420}-0\right)^{18}$ to use in coupled HPLC-MS enzymatic assays with $M t b$-FbiD. Surprisingly, we found that when $M t b$-FbiD and $M t b$-FbiA were included in an assay with 2-PL, GTP (or ATP) and Fo, no product was formed (Fig. 1b). We then tested whether Mtb-FbiA 
and CofC from Methanocaldococcus jannaschii (Mj-CofC) could catalyze $\mathrm{F}_{420}-0$ formation under the same conditions, which again yielded no product (Fig. 1b).

Although 2-PL is hypothesized to be an intermediate in $\mathrm{F}_{420}$ biosynthesis, this has never been experimentally confirmed in bacteria. Additionally, no enzyme capable of phosphorylating $L$-lactate to 2-PL has been identified in $\mathrm{F}_{420}$ producing organisms, despite considerable investigation ${ }^{22}$. 2-PL has been little studied as a metabolite and is only known to occur as a by-product of pyruvate kinase activity ${ }^{27}$. 2-PL has not been implicated as a substrate in any metabolic pathway outside the proposed role in $\mathrm{F}_{420}$ biosynthesis; rather it has been shown in vitro to inhibit several enzymes involved in glycolysis and amino acid biosynthe$\operatorname{sis}^{28-30}$. Our inability to detect activity with 2-PL led us to consider alternative metabolites that could potentially substitute for 2-PL, namely the structurally analogous and comparatively abundant molecule phosphoenolpyruvate (PEP) ${ }^{31}$ (Fig. 1a).

While there was no activity when 2-PL was used in the FbiD/CofC:FbiA coupled assays, when these enzymes were incubated with PEP, GTP (or ATP) and Fo, a previously unreported intermediate in the $\mathrm{F}_{420}$ biosynthesis pathway, which we term 'dehydro- $\mathrm{F}_{420}-0$ ', was produced (Fig. 1b). The identity of this compound, which is identical to $\mathrm{F}_{420}-0$ except for a methylene group in place of the terminal methyl group, was verified by tandem mass spectrometry (Fig. 1c). The only difference that we observed between $M t b$-FbiD or $M j$-CofC was that while $M t b$-FbiD exclusively utilizes GTP to produce dehydro-F $420-0, M j$-CofC can also catalyze the reaction with ATP, albeit to a lesser extent (Fig. 1b). Interestingly, in our experiments the FbiD/CofC enzymes were only active in the presence of FbiA. This was not unexpected given that the inferred intermediate (enolpyruvyl-diphospho-5'-guanosine; EGGP) is expected to be unstable ${ }^{22}$ (Fig. 1a). 
To understand the molecular basis of PEP recognition by $M t b-\mathrm{FbiD}$, we crystallized the protein and solved the structure by selenium single-wavelength anomalous diffraction (Se-SAD), and then used this selenomethionine-substituted structure to obtain the native FbiD structure by molecular replacement. The latter was then refined at $1.99 \AA$ resolution $\left(\mathrm{R} / \mathrm{R}_{\text {free }}=0.19 / 0.22\right)($ SI Table 2$)$. As expected, $M t b$-FbiD adopts the same MobA-like nucleoside triphosphate (NTP) transferase family protein fold as CofC: a central 7-stranded $\beta$-sheet ( six parallel strands and one antiparallel), with $\alpha$-helices packed on either side (Fig. 2a). Superposition of CofC from Methanosarcina mazei (PDB code 2I5E) on to Mtb-FbiD gives a root mean square difference (rmsd) of $1.85 \AA$ over $181 \mathrm{C} \alpha$ atoms, with $25.4 \%$ sequence identity, establishing clear structural homology.

We also soaked PEP into pre-formed FbiD crystals to obtain an FbiD-PEP complex (2.18 $\AA$ resolution, $\left.\mathrm{R} / \mathrm{R}_{\text {free }}=0.22 / 0.26\right)$. FbiD has a cone-shaped binding cleft with a groove running across the base of the cone, formed by the $\mathrm{C}$-terminal end of the central $\beta$-sheet (Fig. 2a). PEP binds in the cleft with its phosphate group anchored through two $\mathrm{Mg}^{2+}$ ions to three acidic side chains (D116, D188 and D190) (Fig. 2b). The PEP carboxylate group is hydrogen bonded to the hydroxyl group of S166 and the main chain NH groups of T148 and G163. All PEP binding residues are conserved in the CofC protein of M. mazei (PDB code 2I5E) (Fig. 2c and Fig. S2), consistent with the enzymatic assays that showed PEP is the substrate for archaeal CofC, as well as FbiD. In the GTP-bound structure of E. coli MobA ${ }^{32}$ (PDB code 1FRW), GTP binds in a characteristic surface groove, providing a structural framework for substrate binding and catalysis. In our enzyme assays, neither FbiD nor CofC showed activity in the absence of FbiA. Moreover, we did not observe GTP binding in either our co-crystallization or differential scanning fluorimetry experiments. We speculate that the GTP binding 
site is not formed until FbiD/CofC interacts with FbiA/CofD, enabling catalysis to proceed through to formation of dehydro- $\mathrm{F}_{420}-0$. This may provide an advantage by producing EPPG/EPPA only when both proteins are available, thereby overcoming the issue of intermediate instability.

\section{The C-terminal domain of FbiB catalyzes reduction of dehydro-F $\mathrm{F}_{420}-0$ to $\mathrm{F}_{420}-0$}

Dehydro- $\mathrm{F}_{420}-0$ would yield $\mathrm{F}_{420}-0$ upon reduction of the terminal methylene double bond. However, no masses corresponding to $\mathrm{F}_{420}-0$ were identified in any of the LC-MS traces from the FbiD:FbiA coupled assays, suggesting that an enzyme other than FbiD or FbiA catalyzes dehydro- $\mathrm{F}_{420}-0$ reduction. We have previously shown that full-length FbiB consists of two domains: an N-terminal domain that is homologous to the archaeal $\gamma$-glutamyl ligase $\operatorname{CofE}^{21,33}$, and a C-terminal domain of the NTR fold ${ }^{34}$ that binds to FMN and has no known function $^{20}$, but is essential for extending the poly- $\gamma$-glutamate tail.

We tested whether FbiB could use dehydro- $\mathrm{F}_{420}-0$ as a substrate with a three enzyme assay in which FbiB and $L$-glutamate were added to the FbiD:FbiA coupled assay. $M t b$-FbiB was observed to catalyze the addition of $L$-glutamate residues to dehydro- $\mathrm{F}_{420}-0$, forming dehydro-F 420 species with one $\left([\mathrm{M}+\mathrm{H}]^{+}, m / z\right.$ of 643.40$)$ and two $\left([\mathrm{M}+\mathrm{H}]^{+}, m / z\right.$ of 772.40$)$ glutamate residues (Fig. S1). We then tested the hypothesis that the orphan function of the FMNbinding C-terminal domain could in fact be a dehydro- $\mathrm{F}_{420}-0$ reductase. We used a four-enzyme in vitro assay where $E$. coli $\mathrm{NAD}(\mathrm{P}) \mathrm{H}$ :flavin oxidoreductase ${ }^{35}$ (Fre), FMN, NADH and $10 \mathrm{mM}$ dithiothreitol (to maintain reducing conditions and generate reduced $\mathrm{FMNH}_{2}$ ) were added to the FbiD:FbiA:FbiB assay and the reaction was performed in anaerobic conditions (to prevent reaction of $\mathrm{FMNH}_{2}$ with oxygen). We found that $\mathrm{F}_{420}-1$, i.e. the fully reduced and 
mature glutamylated cofactor, was produced; but only in the presence of both FbiB and Fre/FMNH 2 (Fig. 3a). Thus, dehydro- $\mathrm{F}_{420}-0$ is a bona fide metabolic intermediate that can be converted to mature $\mathrm{F}_{420}$ by $\mathrm{FbiB}$ in an $\mathrm{FMNH}_{2}$-dependent fashion. These results demonstrate that bacterial $\mathrm{FbiB}$ is a bifunctional enzyme, functioning as a dehydro- $\mathrm{F}_{420}-0$ reductase and as a $\gamma$-glutamyl ligase (Fig. 3c).

When the previously published crystal structures of $M t b$-FbiB are analyzed in the context of these results, the molecular basis for this activity becomes clear. Crystal structures with both $\mathrm{F}_{420}$ and FMN bound have been separately solved and when these are overlaid, it is apparent that the FMN molecule is ideally situated to transfer a hydride to the terminal methylene of dehydro- $\mathrm{F}_{420}-0$ (assuming deydro- $\mathrm{F}_{420}-0$ binds in a similar fashion to $\mathrm{F}_{420}$ ). Interestingly, the phospholactyl group of $\mathrm{F}_{420}$ appears to be disordered in these crystal structures, suggesting it may adopt multiple conformations. To test this, we docked and minimized dehydro- $\mathrm{F}_{420}-0$ and $\mathrm{FMNH}_{2}$ simultaneously using the OPSL3a forcefield. The results show that in this ternary complex the two molecules can adopt ideal positions and orientations for the reduction of dehydro- $\mathrm{F}_{420}-0$ (Fig. $3 \mathrm{~b}$ ). The methylene group of dehydro- $\mathrm{F}_{420}-0$ is accommodated by a small hydrophobic pocket mostly comprised of P289 and M372 allowing it to be positioned above the $\mathrm{N} 5$ atom of $\mathrm{FMNH}_{2}$, in a plausible Michaelis complex for hydride transfer. We therefore suggest that the phosphoenolpyruvyl (analogous to the phospholactyl) group of dehydro-F $420-0$ most likely samples conformations within this pocket where it can be reduced.

Interestingly, the $\gamma$-glutamyl ligase CofE from archaea is a single domain enzyme; there is no homology to the C-terminal NTR-fold domain of FbiB. In an analogous situation, 
Fo synthesis is performed by two single domain enzymes in archaea, CofH and $\mathrm{CofG}^{2}$, whereas in bacteria this reaction is catalyzed by a two-domain protein, FbiC (with $\mathrm{N}$ - and Cterminal domains homologous to $\mathrm{CofH}$ and $\mathrm{CofG}$, respectively). Previous analysis of archaeal genomes revealed that $c o f H$ and $c o f G$ are closely associated in genomic context ${ }^{36}$. We therefore investigated the genomic context of archaeal cofE genes to investigate whether genes with homology to the C-terminal NTR domain of FbiB were located nearby. From over 1000 archaeal genomes, we only detected 16 open reading frames (ORFs) in the neighboring context of cofE that could encode proteins with an NTR fold, although none of these shared substantial (>34\% sequence identity) homology and all lacked the key $\mathrm{F}_{420}$ binding residues ob-

served in FbiB. There was one interesting exception: the unusual archaea Lokiarchaeum sp. ${ }^{37}$ are unique among all sequenced archaea in that they alone encode an FbiB-like $\gamma$-glutamyl ligase:NTR fusion protein.

\section{A recombinant $\mathrm{F}_{420}$ biosynthesis operon can be heterologously expressed in Escherichia coli to produce mature $\mathbf{F}_{420}$}

Cofactor $\mathrm{F}_{420}$ is only produced by certain bacterial species; the majority of bacteria, including Escherichia coli, lack the genes required for $\mathrm{F}_{420}$ biosynthesis. Our in vitro assay results suggest that 2-PL, and by extension, the hypothesized $L$-lactate kinase CofB, are not required for heterologous production of $\mathrm{F}_{420}$ in a non-native organism. To test our hypothesis, we generated a plasmid expressing the Mycobacterium smegmatis $\mathrm{F}_{420}$ biosynthesis genes $f b i B / C / D$ along with the fbiA homolog cofD from Methanosarcina mazei ${ }^{19}$, which was substituted as $M s$-FbiA was found to express poorly in E. coli. 
We generated two versions of a plasmid-encoded recombinant $\mathrm{F}_{420}$ biosynthetic operon, both of which encode codon-optimized genes for expression in E. coli: one encodes the native enzymes $\left(\mathrm{pF}_{420}\right)$, and the second encodes C-terminal FLAG-tagged versions of the enzymes to allow their detection in a western blot ( $\mathrm{pF}_{420}$-FLAG) (Fig. 4a). Plasmids were designed to allow induction of $\mathrm{F}_{420}$ biosynthesis in the presence of anhydrotetracycline. A western blot using anti-FLAG antibodies was used to detect whether the proteins were expressed in soluble form in E. coli, and confirmed that all were expressed to varying degrees (Fig. S3). We then tested, using HPLC with fluorescence detection, whether $\mathrm{F}_{420}$ was heterologously produced in the cell lysate of our recombinant E. coli strain expressing this operon. As shown in Fig. 4b, E. coli expressing both the FLAG-tagged, and untagged, plasmids produced traces consistent with mature, poly-glutamylated $\mathrm{F}_{420}$, although they differed slightly to the $M$. smegmatis produced $\mathrm{F}_{420}$ standard in terms of the distribution of poly- $\gamma$-glutamate tail lengths.

To confirm that this was indeed mature $\mathrm{F}_{420}$, and not dehydro- $\mathrm{F}_{420}$ species, we purified the compound from E. coli lysate and performed high-resolution MS/MS analysis. Mass fragmentation did indeed show that the compound was reduced, and not dehydro-F 420 (Fig. 4d). No dehydro-F $\mathrm{F}_{420}$ species were detected. The yield of purified $\mathrm{F}_{420}$ was approximately 27 $\mathrm{nmol} / \mathrm{L}$ of culture, which is comparable to physiological levels of several $\mathrm{F}_{420}$-producing spe$\operatorname{cies}^{38}$. UV-Vis and fluorescence spectra of the purified $\mathrm{F}_{420}$ matched literature values (Fig. S4) $)^{4,5}$. Finally, we confirmed that the purified cofactor was functional by measuring enzyme kinetic parameters with $\mathrm{F}_{420}$-dependent glucose-6-phosphate dehydrogenase (FGD) from $M$. smegmatis (Fig. 4c). The apparent Michaelis constant was within error of that observed with FGD and $\mathrm{F}_{420}$ produced from $M$. smegmatis, while the $k_{\text {cat }}$ was approximately half that of the M. smegmatis $\mathrm{F}_{420}$ (Fig. 4c), which could result from slight differences in the distribution of 
tail lengths, as previously reported (Table S3) ${ }^{39}$. These results confirm that the recombinant production of $\mathrm{F}_{420}$ was achieved with a biosynthetic pathway containing only CofD (equivalent to $\mathrm{FbiA} / \mathrm{FbiB} / \mathrm{FbiC} / \mathrm{FbiD}$.

\section{Discussion}

It has become widely accepted within the field that one of the essential initial steps in $\mathrm{F}_{420}$ biosynthesis involves a hypothetical $L$-lactate kinase that produces 2-PL, which is subsequently incorporated into $\mathrm{F}_{420}$ through the activities of $\mathrm{CofC}$ and CofD. However, neither bioinformatics nor genetic knockout studies have identified plausible candidate genes for a $L$-lactate kinase $^{2,18,23}$. Furthermore, 2-PL has been shown to inhibit several enzymes involved in central metabolism ${ }^{28-30}$. In terms of pathway flux, this makes 2-PL an unusual starting point for biosynthesis of an abundant metabolite such as $\mathrm{F}_{420}$, which can exceed $1 \mu \mathrm{M}$ in some species ${ }^{38}$. The results presented in this paper unequivocally demonstrate that PEP, rather than 2-PL, is the authentic starting metabolite in bacteria. These results reconcile the previously problematic assumptions that are required to include 2-PL within the biosynthetic pathway and establish a revised pathway (Fig. 5) that is directly linked to central carbon metabolism (via PEP) through the glycolysis and gluconeogenesis pathways.

Our observation that CofC accepts PEP (and not 2-PL) in vitro, appear to contradict previous studies in which $M j$-CofC was reported to use 2-PL as substrate ${ }^{19,33}$. However, this discrepancy is most likely due to the supplementation of the coupled CofC/CofD reaction in these studies with pyruvate kinase and $2 \mathrm{mM}$ PEP, a strategy that was used to overcome apparent product inhibition by GMP ${ }^{19,33}$. Regardless, we cannot explain how a pathway starting from PEP can produce mature (i.e. not dehydro- $\mathrm{F}_{420}$ ) $\mathrm{F}_{420}$ in archaea given that their equivalent of FbiB (CofE) lacks the $\mathrm{C}$-terminal domain dehydro- $\mathrm{F}_{420}-0$ reductase domain seen in 
FbiB. One possibility is that an unknown dehydro- $\mathrm{F}_{420}-0$ reductase exists elsewhere in the genome (remote from CofE). Further studies are required to resolve this step in archaeal $\mathrm{F}_{420}$ biosynthesis.

The discovery of dehydro- $\mathrm{F}_{420}-0$ as the product of FbiD:FbiA activity in mycobacteria indicated that another enzyme must be required to reduce dehydro- $\mathrm{F}_{420}-0$ and produce $\mathrm{F}_{420}-0$. This allowed us to define the function of the orphan C-terminal domain of mycobacterial $\mathrm{FbiB}^{20}$. The N-terminal domain is homologous with the archaeal $\gamma$-glutamyl ligase $\mathrm{CofE}^{33}$, but is only capable of catalyzing glutamylation of $\mathrm{F}_{420}-1^{20}$. The C-terminal domain, which binds both $\mathrm{F}_{420}$ and FMN, is essential for extending the poly- $\gamma$-glutamate tail of $\mathrm{F}_{420}-0^{20}$, but we could not explain the possible function of the FMN cofactor. Here, we show that FbiB can catalyze both poly-glutamylation and reduction of dehydro- $\mathrm{F}_{420}-0$, via the activities of the $\mathrm{N}$ and C-terminal domains, respectively.

The increasing recognition of the importance of $\mathrm{F}_{420}$ in a variety of biotechnological, medical and ecological contexts underlines the need for making the compound more widely accessible to researchers; however our inability to produce $\mathrm{F}_{420}$ recombinantly in common laboratory organisms has been a major barrier to wider study. Here, we confirm the results of our in vitro experiments by showing that recombinant expression of the four characterized $\mathrm{F}_{420}$ biosynthesis genes allows production of $\mathrm{F}_{420}$ in $E$. coli. This should now facilitate the use of $\mathrm{F}_{420}$ in a variety of processes with recombinant organisms, such as biocatalysis using a bioorthogonal cofactor, directed evolution of $\mathrm{F}_{420}$-dependent enzymes, recombinant production of antibiotics for which $\mathrm{F}_{420}$ is a required cofactor, and metabolic engineering. 


\section{Methods}

\section{Bacterial strains and growth conditions}

Protein expression utilized either M. smegmatis $\mathrm{mc}^{2} 4517^{40}$, E. coli BL21(DE3) or LOBSTRBL21(DE3 $)^{41}$ cells. For growth of M. smegmatis, media were supplemented to $0.05 \%(v / v)$ Tween80. M. smegmatis cells were grown in ZYM-5052 $2^{42}$ or modified auto-induction media TB $2.0\left(2.0 \%\right.$ tryptone, $0.5 \%$ yeast extract, $0.5 \% \mathrm{NaCl}, 22 \mathrm{mM} \mathrm{KH}_{2} \mathrm{PO}_{4}, 42 \mathrm{mM} \mathrm{Na}_{2} \mathrm{HPO}_{4}$, $0.6 \%$ glycerol, $0.05 \%$ glucose, $0.2 \%$ lactose $)^{43}$. For selenomethionine labelling, cells were grown in PASM-5052 media ${ }^{42}$. E. coli expressions were conducted in either the above modified auto-induction media, or Terrific Broth (TB) medium modified for auto-induction of protein expression (1.2\% tryptone, $2.4 \%$ yeast extract, $72 \mathrm{mM} \mathrm{K}_{2} \mathrm{HPO}_{4}, 17 \mathrm{mM} \mathrm{KH}_{2} \mathrm{PO}_{4}, 2 \mathrm{mM}$ $\mathrm{MgSO}_{4}, 0.8 \%$ glycerol, $0.015 \%$ glucose, $0.5 \%$ lactose, $0.375 \%$ aspartic acid), grown for $4 \mathrm{~h}$ at $37^{\circ} \mathrm{C}$ followed by overnight incubation at $18^{\circ} \mathrm{C}$.

\section{Protein expression and purification}

$M t b$-FbiD. The open reading frame encoding FbiD (Rv2983) was obtained by PCR from $M$. tuberculosis genomic DNA (Table S1). The pYUBDuet-fbiABD co-expression construct was then prepared by cloning fbiD into pYUBDuet ${ }^{44}$ using BamHI and HindIII restriction sites, followed by cloning the $f b i A B$ operon using NdeI and PacI restriction sites. This construct expresses FbiD with an N-terminal His6-tag, whereas the FbiA and FbiB proteins are expressed without any tags.

The pYUBDuet-fbiABD vector was transformed into $M$. smegmatis $\mathrm{mc}^{2} 4517 \operatorname{strain}^{40}$ for expression. The cells were grown in a fermenter (BioFlo ${ }^{\circledR} 415$, New Brunswick Scientific) 
for 4 days before harvesting. The cells were lysed in $20 \mathrm{mM}$ HEPES, $\mathrm{pH} 7.5,150 \mathrm{mM} \mathrm{NaCl}$, $20 \mathrm{mM}$ imidazole, $1 \mathrm{mM} \beta$-mercaptoethanol using a cell disruptor (Microfluidizer M-110P) in the presence of Complete protease inhibitor mixture mini EDTA-free tablets (Roche Applied Science). The lysate was centrifuged at $20,000 \times g$ to separate the insoluble material. Recombinant FbiD was separated from other proteins by immobilized metal affinity chromatography (IMAC) on a HisTrap FF 5-ml Ni-NTA column (GE Healthcare), eluted with imidazole, and further purified by Size Exclusion Chromatography (SEC) on a Superdex 75 10/300 column (GE Healthcare) pre-equilibrated in $20 \mathrm{mM}$ HEPES, pH 7.5, $150 \mathrm{mM} \mathrm{NaCl}, 1 \mathrm{mM} \beta$ mercaptoethanol.

Mtb-FbiA. The open reading frame encoding M. tuberculosis FbiA was commercially synthesized and cloned into pRSET-A (Invitrogen). The pYUB28b-fbiA construct used for expression in $M$. smegmatis $\mathrm{mc}^{2} 4517$ was prepared by subcloning $f b i A$ into $\mathrm{pYUB} 28 \mathrm{~b}^{44}$ using an NdeI site introduced by overhang PCR utilizing the HindIII restriction site present on both vectors amplified with the T7 reverse primer (Table S1). The resulting pYUB28b- $f b i A$ construct expresses FbiA with an N-terminal His6-tag. The protein was expressed in M. smegmatis $\mathrm{mc}^{2} 4517$ in ZYM-5052 media auto-induction media ${ }^{42,45}$ in a fermenter (BioFlo ${ }^{\circledR} 415$, New Brunswick Scientific) for 4 days. The protein was then purified using Ni-NTA and size-exclusion chromatography steps, as described above, in $20 \mathrm{mM}$ HEPES, pH 7.5, $200 \mathrm{mM} \mathrm{NaCl,}$ $5 \%$ glycerol, $1 \mathrm{mM} \beta$-mercaptoethanol.

Mj-CofC. The open reading frame encoding Methanocaldococcus jannaschii CofC $(\mathrm{MJ} 0887)^{25}$ was synthesized (GenScript) and cloned into pYUB28b vector ${ }^{44}$ using NdeI and HindIII restriction sites. The protein was expressed in TB auto-induction media and purified 
using Ni-NTA and size-exclusion chromatography steps, as described above, in $20 \mathrm{mM}$

HEPES, pH 7.5, $200 \mathrm{mM} \mathrm{NaCl,} \mathrm{5 \%} \mathrm{glycerol,} 1 \mathrm{mM} \beta$-mercaptoethanol.

$E c$-Fre. The E. coli flavin reductase ${ }^{35}$ was cloned into pProEX-HTb using KasI and HindIII restriction sites (Table S1). Protein expression and purification was performed similar to $M j$-CofC.

$M s$-FbiD. The open reading frame encoding M. smegmatis FbiD (MSMEG_2392) was synthesized (Integrated DNA Technologies) and cloned into pETMCSIII by Gibson Assembly as outlined previously ${ }^{43}$. The protein was expressed overnight ay $30^{\circ} \mathrm{C}$ in auto-induction media and purified similarly to $M j$-CofC.

\section{Construction of synthetic F420 biosynthesis operon}

Ribosome binding sites were individually optimized for each of the codon-optimized $\mathrm{F}_{420}$ biosynthesis genes using the Ribosome Binding Site Calculator server ${ }^{36,46}$. Multiple operon designs were analyzed using the server's operon calculator and modified to remove unwanted translation products and RNA instability elements while maintaining predicted translation initiation rates for all coding sequences within an order of magnitude. The final design placed the operon under the control of the tetracycline-inducible promoter BBa_R0040 and the artificial terminator BBa_B1006. For subsequent assembly the operon was flanked by BioBrick prefix and suffix sequences. The operon was synthesized by GenScript and cloned into pSB1C3 containing the constitutive tetracycline repressor cassette BBa_K145201 using the standard BioBrick assembly protocol with EcoRI and XbaI/SpeI restriction enzymes ${ }^{47}$.This construct, hereafter referred to as $\mathrm{pF}_{420}$, allowed for production of $\mathrm{F}_{420}$ to be induced by the 
addition of anhydrotetracycline. For western blot analysis as second version of the operon with single C-terminal FLAG tags on all four genes was likewise synthesized.

To test for in vivo $\mathrm{F}_{420}$-depended reductase/oxidase activity the open reading frame of M. smegmatis FGD (MSMEG_0777) was codon optimized and commercially synthesized by GenScript and cloned into multiple cloning site 1 of pCOLADuet-1 (Novagen) using NcoI and HindIII sites. Subsequently MSMEG_2027 was subcloned from pETMCSIIIMSMEG_2027 $7^{43}$ into multiple cloning site 2 using NdeI and KpnI to give pFGD2027.

\section{Mtb-FbiD crystallization and structure determination}

Crystallization. Apo-FbiD (20 mg/mL in $20 \mathrm{mM}$ HEPES pH 7.5, $150 \mathrm{mM} \mathrm{NaCl}, 1 \mathrm{mM} \beta-$ mercaptoethanol) was crystallized using the sitting drop vapor diffusion method in $30 \%$ PEG 1500, 3\% MPD, 0.2 $\mathrm{M} \mathrm{MgSO}_{4}, 0.1 \mathrm{M}$ sodium acetate $\mathrm{pH}$ 5.0. For experimental phasing, selenomethionine-substituted FbiD crystals were grown using protein produced in M. smegmatis host cells ${ }^{45}$. Se-SAD anomalous diffraction data sets were collected at the Australian Synchrotron. Data collection statistics are summarized in Table S2. Crystals of Mtb-FbiD in complex with PEP were obtained by soaking pre-formed apo crystals in precipitant solutions containing $10 \mathrm{mM}$ PEP for $30 \mathrm{~min}$.

Structure determination. All data sets were indexed and processed using $\mathrm{XDS}^{48}$, and scaled with AIMLESS ${ }^{49}$ from the CCP4 program suite ${ }^{50}$. The structure was solved using the SAD protocol of Auto-Rickshaw ${ }^{51}$, the EMBL-Hamburg automated crystal structure determination platform. Based on an initial analysis of the data, the maximum resolution for substructure determination and initial phase calculation was set to $2.83 \AA$. All three of the ex- 
pected heavy atoms were found using the program SHELXD ${ }^{52}$. The initial phases were improved using density modification and phase extension to $2.33 \AA$ resolution using the program RESOLVE ${ }^{53}$. Cycles of automatic model building by ARP/wARP ${ }^{54}$ and phenix.autobuild $^{55}$ resulted in a protein model that was completed manually using COOT $^{56}$. Water molecules were identified by their spherical electron density and appropriate hydrogen bond geometry with the surrounding structure. Following each round of manual model building, the model was refined using REFMAC $5^{57}$, against the data to $1.99 \AA$ resolution. The PDB_redo program $^{58}$ was used in the final stages of refinement. Full refinement statistics are shown in Table S2.

The structure of $M t b$-FbiD in complex with PEP was solved by molecular replacement using PHASER ${ }^{59}$ with the apo-FbiD structure as a search model. The structure was refined by cycles of manual building using $\mathrm{COOT}^{56}$ and refinement using REFMAC5 ${ }^{57}$, against the data to $2.18 \AA$ A resolution. Full refinement statistics are shown in Table S2.

\section{HPLC assays}

FbiD/CofC-FbiA coupled activity was monitored in a reaction mixture containing $100 \mathrm{mM}$ HEPES pH 7.5, 2 mM GTP, $0.1 \mathrm{mM}$ Fo, $5 \mathrm{mM} \mathrm{MgCl} 2,1 \mathrm{mM}$ 2-PL or PEP, $1 \mu \mathrm{M}$ FbiD and 5 $\mu \mathrm{M}$ FbiA. The reactions were incubated at $37^{\circ} \mathrm{C}$ and stopped using $20 \mathrm{mM}$ EDTA at various time points. Separation of $\mathrm{F}_{420}$ species was performed on an Agilent HP 1100 HPLC system equipped with photodiode array and fluorescence detectors (Agilent Technologies). Samples were kept at $4^{\circ} \mathrm{C}$, and the injection volume was $20 \mu \mathrm{L}$. Samples were separated on a Phenomenex Luna C18 column $(150 \times 3 \mathrm{~mm}, 5 \mu \mathrm{m})$ with a $0.2 \mu \mathrm{m}$ in-line filter that was maintained at $30{ }^{\circ} \mathrm{C}$. The mobile phase consisted of $100 \%$ methanol (A) and $25 \mathrm{mM}$ sodium acetate 
buffer, $\mathrm{pH} 6.0(\mathrm{~B})$, with a gradient elution at a flow rate of $0.5 \mathrm{ml} / \mathrm{min}$ and a run time of 30 min. The gradient profile was performed as follows: $0-25 \min 95-80 \% \mathrm{~B}, 25-26 \min 80 \% \mathrm{~B}$, 26-27 $\min 95 \% \mathrm{~B}, 27-30 \mathrm{~min} 95 \% \mathrm{~B}$, and a post-run of $2 \mathrm{~min}$. The wavelengths used for photodiode array were 280 and $420 \mathrm{~nm}$ (bandwidth $20 \mathrm{~nm}$ ) using a reference of $550 \mathrm{~nm}$ (bandwidth $50 \mathrm{~nm}$ ). The wavelengths used for the fluorescence detector were $420 \mathrm{~nm}$ (excitation) and $480 \mathrm{~nm}$ (emission).

\section{LC-MS characterization of dehydro-F 420 species}

Enzymatic reactions were set up as described above. $10 \mathrm{uL}$ aliquots were injected onto a C18 trap cartridge (LC Packings, Amsterdam, Netherlands) for desalting prior to chromatographic separation on a $0.3 \times 100 \mathrm{~mm} 3.5 \mu \mathrm{m}$ Zorbax 300SB C18 Stablebond column (Agilent Technologies, Santa Clara, CA, USA) using the following gradient at $6 \mathrm{uL} / \mathrm{min}$ : 0-3 min 10\% B,

$24 \min 50 \%$ B, $26 \min 97 \%$ B, $29 \min 97 \%$ B, $30.5 \min 10 \%$ B, $35 \min 10 \%$ B, where A was $0.1 \%$ formic acid in water and B was $0.1 \%$ formic acid in acetonitrile. The column eluate was ionised in the electrospray source of a QSTAR-XL Quadrupole Time-of-Flight mass spectrometer (Applied Biosystems, Foster City, CA, USA). For IDA (Information Dependent Analysis) analyses, a TOF-MS scan from 330-1000 m/z was performed, followed by three rounds of MS/MS on the most intense singly or doubly charged precursors in each cycle. For targeted work, defined Product Ion Scans were created to isolate and fragment specific ions of interest with various collision energies $(10-60 \mathrm{kV})$. Both positive and negative modes of ionisation were used as appropriate.

\section{MS/MS confirmation of reduction of dehydro-F 420 species}


To confirm the reduction of the PEP moiety in vitro assays were prepared in $50 \mathrm{mM}$ HEPES pH 7.5, $100 \mathrm{mM} \mathrm{KCl,} 5 \mathrm{mM} \mathrm{MgCl} 2,2 \mathrm{mM}$ GTP, $0.1 \mathrm{mM}$ Fo, 1 mM PEP, $5 \mu \mathrm{M}$ Mtb-FbiA, $6.5 \mu \mathrm{M} M s g$-FbiD, 10 mM DTT, $20 \mu \mathrm{M}$ FMN, $0.2 \mathrm{mM}$ NADH, $0.1 \mu \mathrm{M} E c$-Fre, $2 \mu \mathrm{M} M t b$ FbiB and $1 \mathrm{mML}$-glutamate. To minimize futile oxidation of $\mathrm{FMNH}_{2}$ by oxygen the reaction mixture was repeatedly evacuated and purged with nitrogen and maintained under a nitrogen atmosphere. Samples were incubated at ambient temperature for up to 36 hours and stopped by addition of $20 \mathrm{mM}$ EDTA. Samples were desalted using Bond Elut C18 tips (Agilent Technologies) and eluted in $0.1 \%$ formic acid in acetonitrile. Samples were injected on to a Q Exactive Plus (ThermoFischer Scientific) at $100 \mu \mathrm{l} / \mathrm{min}$ with isocratic 50\% B where A was $10 \mathrm{mM}$ ammonium acetate $\mathrm{pH} 6.0$ and B was $0.02 \%$ ammonia in methanol. Scans from 150$2250 \mathrm{~m} / \mathrm{z}$ were performed and data-dependent MS/MS on targeted metabolites was done in both positive and negative mode.

\section{Production of $\mathbf{F}_{420}$ in $E$. coli}

The $\mathrm{pF}_{420}$ vector was transformed into E. coli BL21(DE3) for expression. Cells were cultivated in M9 minimal media supplemented with chloramphenicol $(25 \mu \mathrm{g} / \mathrm{mL})$ and tyrosine $(18$ $\mu \mathrm{g} / \mathrm{mL}$ ) in $1 \mathrm{~L}$ shake flasks with $500 \mathrm{ml}$ working volume at $28{ }^{\circ} \mathrm{C}$. At O.D. of $0.60,200$ $\mathrm{ng} / \mathrm{mL}$ of tetracycline was added to induce the expression of $\mathrm{F}_{420}$ biosynthesis pathway. After induction, cells were cultivated for at least $16 \mathrm{~h}$. To test expression of the $\mathrm{F}_{420}$ biosynthetic genes, cell pellets were lysed by resuspending to O.D. of 0.8 in buffer containing BugBuster (Novagen). Following centrifugation at $16,000 \times g$ proteins were resolved on a gel $\left(\right.$ Bolt $^{\mathrm{TM}} 4$ 12\% Bis-Tris Plus, Invitrogen) for $1 \mathrm{~h}$ and visualized using Coomassie Brilliant Blue. For immunoblotting, proteins were transferred to a membrane (iBlot ${ }^{\circledR} 2 \mathrm{NC}^{\mathrm{Regular}}$ Stacks, Invitrogen) using iBlot Invitrogen (25 V, 6 mins). After staining and de-staining, the membrane was 
blocked with $3 \%$ skim milk solution and blotted with anti-FLAG antibodies conjugated with HRP (DYKDDDDK Tag Monoclonal Antibody, Thermofisher Scientific).

For detection of $\mathrm{F}_{420}$ in E. coli lysate by HPLC-FLD, cells were grown overnight in media containing $2.0 \%$ tryptone, $0.5 \%$ yeast extract, $0.5 \% \mathrm{NaCl}, 22 \mathrm{mM} \mathrm{KH}_{2} \mathrm{PO}_{4}, 42 \mathrm{mM}$ $\mathrm{Na}_{2} \mathrm{HPO}_{4}, 100 \mathrm{ng} / \mathrm{mL}$ anhydrotetracycline, $34 \mu \mathrm{g} / \mathrm{mL}$ chloramphenicol at $30{ }^{\circ} \mathrm{C}$. Cells from $500 \mu \mathrm{L}$ of culture were pelleted by centrifugation at $16,000 \times g$. Cells were resuspended in $500 \mu \mathrm{L}$ of $50 \mathrm{mM} \mathrm{Na}_{2} \mathrm{HPO}_{4} \mathrm{pH} 7.0$ and lysed by boiling at $95{ }^{\circ} \mathrm{C}$ for 10 minutes. Cell debris was pelleted by centrifugation at $16,000 \times g$ and filtered through a $0.22 \mu \mathrm{m}$ PVDF filter. Analysis was conducted as described previously ${ }^{2}$.pSB1C3 containing only BBa_K145201 was used as a control.

\section{Purification and analysis of $E$. coli -produced $F_{420}$}

For $\mathrm{F}_{420}$ extraction, $1 \mathrm{~L}$ of cell culture was centrifuged at 5,000 $\times g$ for 15 minutes. The cell pellet was re-suspended in $30 \mathrm{ml}$ of $75 \%$ ethanol and boiled at $90{ }^{\circ} \mathrm{C}$ in a water bath for $6 \mathrm{~min}$ for cell lysis. The cell extract was again centrifuged at 5,000 $\times g$ for 15 minutes to remove cell debris and the supernatant was lyophilized. The lyophilized cell extract was re-dissolved in $10 \mathrm{ml}$ milli Q water centrifuged at 5,000 $\times \mathrm{g}$ for 15 minutes and the supernatant passed through $0.45 \mu \mathrm{m}$ syringe filter (Millex-HV). The filtered cell extract was purified for $\mathrm{F}_{420}$ using a $5 \mathrm{ml}$ HiTrap QFF column (GE Healthcare) as previously described ${ }^{44}$. The purified $\mathrm{F}_{420}$ solution was further desalted by passing it through C18 extract column (6 ml, HyperSep C18 Cartridges, ThermoFischer Scientific). The C18 extract column was first equilibrated by passing through $10 \mathrm{ml}$ of $100 \%$ methanol and $10 \mathrm{ml}$ of milli Q. Afterwards the $\mathrm{F}_{420}$ solution was passed through the C18 extract column, $\mathrm{F}_{420}$ was eluted in $2 \mathrm{ml}$ fraction of $20 \%$ methanol. 
The purified $\mathrm{F}_{420}$ solution was further concentrated in GeneVac RapidVap and re-dissolved in $500 \mu 1$ of milliQ for further analysis and assays.

UV and fluorescence spectra were collected on a Varian Cary 60 and a Varian Cary Eclipse, respectively, in a $10 \mathrm{~mm}$ QS quartz cell (Hellma Analytics). Samples were buffered to $\mathrm{pH} 7.5$ with $50 \mathrm{mM}$ HEPES and scanned from 250-600 nm. For fluorescence, the excitation wavelength was $420 \mathrm{~nm}$ and the emission scanned from 435 to $600 \mathrm{~nm}$.

Activity assays with $M$. smegmatis and E. coli-derived $\mathrm{F}_{420}$ were conducted with $M$. smegmatis FGD1 expressed and purified as described previously ${ }^{15}$. Assays were performed in $50 \mathrm{mM}$ Tris pH 7.5, $300 \mathrm{mM} \mathrm{NaCl,} 50 \mathrm{nM}$ FGD1, $5 \mu \mathrm{M} \mathrm{F}_{420}$ and 0-1000 $\mu \mathrm{M}$ glucose-6-phosphate using a SpectraMAX e2 plate reader. Activity was measured by following loss of $\mathrm{F}_{420}$ fluorescence at $470 \mathrm{~nm}$. Apparent $k_{\text {cat }}$ and $K_{\mathrm{m}}$ values were calculated using GraphPad Prism 7.04 (GraphPad Software, La Jolla California).

\section{2-PL synthesis}

In the absence of a commercial source, 2-PL was chemically synthesized by a slight modification of the method of Kirsch ${ }^{60}$. Briefly, benzyl lactate was condensed with chlorodiphenyl phosphate in pyridine, with cooling, to give benzyldiphenylphosphoryl lactate. Hydrogenolysis of this material in $70 \%$ aqueous tetrahydrofuran over $10 \% \mathrm{Pd}-\mathrm{C}$ gave phospholactic acid as a colorless, viscous oil, which was characterized by proton, carbon and phosphorus NMR spectroscopy, and by mass spectrometry. ${ }^{1} \mathrm{H}$ NMR (DMSO-d 6 ) $\delta 11.68(\mathrm{br}, 3 \mathrm{H}), 4.53(\mathrm{~m}, 1 \mathrm{H})$, $1.36(\mathrm{~d}, \mathrm{~J}=6.8 \mathrm{~Hz}, 3 \mathrm{H}) .{ }^{13} \mathrm{C} \mathrm{NMR}\left(\mathrm{DMSO}_{-} \mathrm{d}_{6}\right) \delta 172.50\left(\mathrm{~d}, \mathrm{~J}_{\mathrm{P}-\mathrm{C}}=0.05 \mathrm{~Hz}\right), 69.56\left(\mathrm{~d}, \mathrm{~J}_{\mathrm{P}-\mathrm{C}}=0.04\right.$ $\mathrm{Hz}), 19.27\left(\mathrm{~d}, \mathrm{~J}_{\mathrm{P}-\mathrm{C}}=0.04 \mathrm{~Hz}\right) .{ }^{31} \mathrm{P}$ NMR $\left(\mathrm{DMSO}-\mathrm{d}_{6}\right) \delta-1.64$. APCI-MS found: $[\mathrm{M}+\mathrm{H}]^{+}=171.1$, $[\mathrm{M}-\mathrm{H}]^{-}=169.1$. 


\section{Fo purification}

Fo was purified from $M$. smegmatis culture medium over-expressing $M t b$-FbiC as described previously ${ }^{44}$.

\section{Genomic context analysis}

A non-redundant CofE dataset of 4,813 sequences was collected using the Pfam identifier PF01996 and the InterPro classifications IPR008225, IPR002847, and IPR023659. Archaeal CofE sequences were extracted from this dataset, resulting in a set of 1,060 sequences that included representatives across twelve phyla: Crenarchaeota, Euryarchaeota, Thaumarchaeota, Candidatus Bathyarchaeota, Candidatus Diapherotrites, Candidatus Heimdallarchaeota, Candidatus Korarchaeota, Candidatus Lokiarchaeota, Candidatus Marsarchaeota, Candidatus Micrarchaeota, Candidatus Odinarchaeota, and Candidatus Thorarchaeota. The genomic context (10 upstream and 10 downstream genes) of each archaeal CofE was analyzed for the presence of a neighboring PF00881 domain with homology to the C-terminal domain of FbiB using the Enzyme Function Initiative - Genome Neighborhood Tool ${ }^{61}$.

\section{Acknowledgment}

We thank Assoc. Prof. Chris Squire, Dr Carol Hartley and Dr Andrew Warden, and Dr Matthew Taylor for helpful discussions, Dr Adam Carroll and Dr Thy Truong for technical assistance. This research is supported by a Sir Charles Hercus Fellowship (GB), an NHMRC New Investigator Grant (CG; 1142699), an ARC DECRA Fellowship (CG; DE170100310), the Health Research Council of New Zealand (ENB), an AGRTP Scholarship (JA), the Australian Research Council, and the National Health and Medical Research Council (CJ). Crystal 
data collection was undertaken on the MX1 beamline at the Australian Synchrotron (Victoria, Australia). Access to the Australian Synchrotron was supported by the New Zealand Synchrotron Group Ltd.

\section{Author contribution}

JA performed experiments, analysed results and cowrote the manuscript; ENMJ, MH, JC,

SMS, SS, BP, MM performed experiments and analyzed results; BN conceived project, per-

formed experiments and analyzed results; CG, ENB conceived project, designed experiments, analyzed results and cowrote the manuscript; CS designed experiments, analyzed results and cowrote the manuscript; GB, CJJ conceived project, designed experiments, performed experiments, analyzed results and cowrote the manuscript. All authors provided feedback on the manuscript.

\section{Declaration of interests}

The authors declare no competing financial interest. 


\section{References}

1 Greening, C. et al. Physiology, Biochemistry, and Applications of $\mathrm{F}_{420}$ - and FoDependent Redox Reactions. Microbiol. Mol. Biol. Rev. 80, 451-493 (2016).

2 Ney, B. et al. The methanogenic redox cofactor $\mathrm{F}_{420}$ is widely synthesized by aerobic soil bacteria. ISME J. 11, 125-137 (2017).

3 Walsh, C. Naturally occurring 5-deazaflavin coenzymes: biological redox roles. Acc. Chem. Res. 19, 216-221 (1986).

4 Cheeseman, P., Toms-Wood, A. \& Wolfe, R. S. Isolation and Properties of a Fluorescent Compound, Factor420, from Methanobacterium Strain M.o.H. J. Bacteriol. 112, 527-531 (1972).

5 Eirich, L. D., Vogels, G. D. \& Wolfe, R. S. Proposed Structure for Coenzyme F420 from Methanobacterium. Biochemistry 17, 4583-4593 (1978).

6 Thauer, R. K., Kaster, A.-K., Seedorf, H., Buckel, W. \& Hedderich, R. Methanogenic archaea: ecologically relevant differences in energy conservation. Nat. Rev. Microbiol. 6, 579-591 (2008).

7 Lackner, G., Peters, E. E., Helfrich, E. J. N. \& Piel, J. Insights into the lifestyle of uncultured bacterial natural product factories associated with marine sponges. Proc. Natl. Acad. Sci. USA 114, E347-E356 (2017).

8 Jay, Z. J. et al. Marsarchaeota are an aerobic archaeal lineage abundant in geothermal iron oxide microbial mats. Nat. Microbiol. 3, 732-740 (2018).

9 Purwantini, E. \& Mukhopadhyay, B. Conversion of $\mathrm{NO}_{2}$ to $\mathrm{NO}$ by reduced coenzyme $\mathrm{F}_{420}$ protects mycobacteria from nitrosative damage. Proc. Natl. Acad. Sci. USA 106, 6333-6338 (2009).

10 Gurumurthy, M. et al. A novel $\mathrm{F}_{420}$-dependent anti-oxidant mechanism protects Mycobacterium tuberculosis against oxidative stress and bactericidal agents. Mol. Microbiol. 87, 744-755 (2013).

11 Singh, R. et al. PA-824 Kills Nonreplicating Mycobacterium tuberculosis by Intracellular NO Release. Science 322, 1392-1395 (2008).

12 Wang, P., Bashiri, G., Gao, X., Sawaya, M. R. \& Tang, Y. Uncovering the Enzymes that Catalyze the Final Steps in Oxytetracycline Biosynthesis. J. Am. Chem. Soc. 135, 7138-7141 (2013).

13 Coats, J. H., Li, G. P., Ming-ST, K. \& Yurek, D. A. Discovery, production, and biological assay of an unusual flavenoid cofactor involved in lincomycin biosynthesis. J. Antibiot. 42, 472-474 (1989).

14 Ichikawa, H., Bashiri, G. \& Kelly, W. L. Biosynthesis of the Thiopeptins and Identification of an $\mathrm{F}_{420} \mathrm{H}_{2}$-Dependent Dehydropiperidine Reductase. J. Am. Chem. Soc. 140, 10749-10756 (2018).

15 Taylor, M. C. et al. Identification and characterization of two families of $\mathrm{F}_{420} \mathrm{H}_{2}-$ dependent reductases from Mycobacteria that catalyse aflatoxin degradation. Mol. Microbiol. 78, 561-575 (2010).

16 Greening, C. et al. Mycobacterial $\mathrm{F}_{420} \mathrm{H}_{2}$-Dependent Reductases Promiscuously Reduce Diverse Compounds through a Common Mechanism. Front. Microbiol. 8 (2017).

17 Graupner, M., Xu, H. \& White, R. H. Characterization of the 2-Phospho-L-lactate Transferase Enzyme Involved in Coenzyme $\mathrm{F}_{420}$ Biosynthesis in Methanococcus jannaschii. Biochemistry 41, 3754-3761 (2002). 
18 Choi, K.-P., Bair, T. B., Bae, Y.-M. \& Daniels, L. Use of Transposon Tn5367 Mutagenesis and a Nitroimidazopyran-Based Selection System To Demonstrate a Requirement for $f b i A$ and $f b i B$ in Coenzyme $\mathrm{F}_{420}$ Biosynthesis by Mycobacterium bovis BCG. J. Bacteriol. 183, 7058-7066 (2001).

19 Forouhar, F. et al. Molecular Insights into the Biosynthesis of the F420 Coenzyme. $J$. Biol. Chem. 283, 11832-11840 (2008).

20 Bashiri, G. et al. Elongation of the Poly- $\gamma$-glutamate Tail of $F_{420}$ Requires Both Domains of the $\mathrm{F}_{420}: \gamma$-Glutamyl Ligase (FbiB) of Mycobacterium tuberculosis. J. Biol. Chem. 291, 6882-6894 (2016).

21 Li, H., Graupner, M., Xu, H. \& White, R. H. CofE Catalyzes the Addition of Two Glutamates to $\mathrm{F}_{420}-0$ in $\mathrm{F}_{420}$ Coenzyme Biosynthesis in Methanococcus jannaschii. Biochemistry 42, 9771-9778 (2003).

22 Graupner, M. \& White, R. H. Biosynthesis of the Phosphodiester Bond in Coenzyme $\mathrm{F}_{420}$ in the Methanoarchaea. Biochemistry 40, 10859-10872 (2001).

23 Guerra-Lopez, D., Daniels, L. \& Rawat, M. Mycobacterium smegmatis mc ${ }^{2} 155$ fbiC and MSMEG_2392 are involved in triphenylmethane dye decolorization and coenzyme $\mathrm{F}_{420}$ biosynthesis. Microbiology 153, 2724-2732 (2007).

24 Rifat, D. et al. Mutations in Rv2983 as a novel determinant of resistance to nitroimidazole drugs in Mycobacterium tuberculosis. Preprint at https://www.biorxiv.org/content/biorxiv/early/2018/10/31/457754.full.pdf (2018).

25 Grochowski, L. L., Xu, H. \& White, R. H. Identification and Characterization of the 2Phospho-L-lactate Guanylyltransferase Involved in Coenzyme $\mathrm{F}_{420}$ Biosynthesis. Biochemistry 47, 3033-3037 (2008).

26 Cole, S. T. et al. Deciphering the biology of Mycobacterium tuberculosis from the complete genome sequence. Nature 393, 537-544 (1998).

27 Ash, D. E., Goodhart, P. J. \& Reed, G. H. ATP-dependent phosphorylation of $\alpha-$ substituted carboxylic acids catalyzed by pyruvate kinase. Arch. Biochem. Biophys. 228, 31-40 (1984).

28 Collard, F. et al. A conserved phosphatase destroys toxic glycolytic side products in mammals and yeast. Nat. Chem. Biol. 12, 601-607 (2016).

29 Walker, S. R., Cumming, H. \& Parker, E. J. Substrate and reaction intermediate mimics as inhibitors of 3-deoxy-D-arabino-heptulosonate 7-phosphate synthase. Org. Biomol. Chem. 7, 3031-3035 (2009).

30 Izui, K., Matsuda, Y., Kameshita, I., Katsuki, H. \& Woods, A. E. Phosphoenolpyruvate Carboxylase of Escherichia coil. Inhibition by Various Analogs and Homologs of Phosphoenolpyruvate. J. Biochem., Tokyo 94, 1789-1795 (1983).

31 Bennett, B. D. et al. Absolute metabolite concentrations and implied enzyme active site occupancy in Escherichia coli. Nat. Chem. Biol. 5, 593-599 (2009).

32 Lake, M. W., Temple, C. A., Rajagopalan, K. V. \& Schindelin, H. The Crystal Structure of the Escherichia coli MobA Protein Provides Insight into Molybdopterin Guanine Dinucleotide Biosynthesis. J. Biol. Chem. 275, $40211-40217$ (2000).

33 Nocek, B. et al. Structure of an Amide Bond Forming F420: $\gamma$-glutamyl Ligase from Archaeoglobus fulgidus - A Member of a New Family of Non-ribosomal Peptide Synthases. J. Mol. Biol. 372, 456-469 (2007). 
34 Akiva, E., Copp, J. N., Tokuriki, N. \& Babbitt, P. C. Evolutionary and molecular foundations of multiple contemporary functions of the nitroreductase superfamily. Proc. Natl. Acad. Sci. USA 114, E9549-E9558 (2017).

35 Fieschi, F., Nivière, V., Frier, C., Décout, J.-L. \& Fontecave, M. The Mechanism and Substrate Specificity of the NADPH:Flavin Oxidoreductase from Escherichia coli. J. Biol. Chem. 270, 30392-30400 (1995).

36 Salis, H. M., Mirsky, E. A. \& Voigt, C. A. Automated design of synthetic ribosome binding sites to control protein expression. Nat. Biotechnol. 27, 946-950 (2009).

37 Spang, A. et al. Complex archaea that bridge the gap between prokaryotes and eukaryotes. Nature 521, 173-179 (2015).

38 Isabelle, D., Simpson, D. R. \& Daniels, L. Large-Scale Production of Coenzyme F4205,6 by Using Mycobacterium smegmatis. Appl. Environ. Microbiol. 68, 5750-5755 (2002).

39 Ney, B. et al. Cofactor Tail Length Modulates Catalysis of Bacterial F420-Dependent Oxidoreductases. Front. Microbiol. 8 (2017).

40 Wang, F. et al. Mycobacterium tuberculosis Dihydrofolate Reductase Is Not a Target Relevant to the Antitubercular Activity of Isoniazid. Antimicrob. Agents Chemother. 54, 3776-3782 (2010).

41 Andersen, K. R., Leksa, N. C. \& Schwartz, T. U. Optimized E. coli expression strain LOBSTR eliminates common contaminants from His-tag purification. Proteins: Struct., Funct., Bioinf. 81, 1857-1861 (2013).

42 Studier, F. W. Protein production by auto-induction in high-density shaking cultures. Protein Expr. Purif. 41, 207-234 (2005).

43 Ahmed, F. H. et al. Sequence-Structure-Function Classification of a Catalytically Diverse Oxidoreductase Superfamily in Mycobacteria. J. Mol. Biol. 427, 3554-3571 (2015).

44 Bashiri, G., Rehan, A. M., Greenwood, D. R., Dickson, J. M. J. \& Baker, E. N. Metabolic Engineering of Cofactor $\mathrm{F}_{420}$ Production in Mycobacterium smegmatis. PLoS One 5, e15803 (2010).

45 Bashiri, G., Squire, C. J., Baker, E. N. \& Moreland, N. J. Expression, purification and crystallization of native and selenomethionine labeled Mycobacterium tuberculosis FGD1 (Rv0407) using a Mycobacterium smegmatis expression system. Protein Expr. Purif. 54, 38-44 (2007).

46 Espah Borujeni, A., Channarasappa, A. S. \& Salis, H. M. Translation rate is controlled by coupled trade-offs between site accessibility, selective RNA unfolding and sliding at upstream standby sites. Nucleic Acids Res. 42, 2646-2659 (2014).

47 Canton, B., Labno, A. \& Endy, D. Refinement and standardization of synthetic biological parts and devices. Nat. Biotechnol. 26, 787 (2008).

48 Kabsch, W. XDS. Acta Crystallogr. D Biol. Crystallogr. 66, 125-132 (2010).

49 Evans, P. Scaling and assessment of data quality. Acta Crystallogr. D Biol. Crystallogr. 62, 72-82 (2006).

50 Winn, M. D. et al. Overview of the CCP4 suite and current developments. Acta Crystallogr. D Biol. Crystallogr. 67, 235-242 (2011).

51 Panjikar, S., Parthasarathy, V., Lamzin, V. S., Weiss, M. S. \& Tucker, P. A. AutoRickshaw: an automated crystal structure determination platform as an efficient tool for 
the validation of an X-ray diffraction experiment. Acta Crystallogr. D Biol. Crystallogr. 61, 449-457 (2005).

52 Schneider, T. R. \& Sheldrick, G. M. Substructure solution with SHELXD. Acta Crystallogr. D Biol. Crystallogr. 58, 1772-1779 (2002).

53 Terwilliger, T. Maximum-likelihood density modification. Acta Crystallogr. D Biol. Crystallogr. 56, 965-972 (2000).

54 Perrakis, A., Morris, R. \& Lamzin, V. S. Automated protein model building combined with iterative structure refinement. Nat. Struct. Biol. 6, 458-463 (1999).

55 Adams, P. D. et al. PHENIX: building new software for automated crystallographic structure determination. Acta Crystallogr. D Biol. Crystallogr. 58, 1948-1954 (2002).

56 Emsley, P. \& Cowtan, K. Coot: model-building tools for molecular graphics. Acta Crystallogr. D Biol. Crystallogr. 60, 2126-2132 (2004).

57 Murshudov, G. N. et al. REFMAC5 for the refinement of macromolecular crystal structures. Acta Crystallogr. D Biol. Crystallogr. 67, 355-367 (2011).

58 Joosten, R. P., Long, F., Murshudov, G. N. \& Perrakis, A. The PDB_REDO server for macromolecular structure model optimization. IUCrJ 1, 213-220 (2014).

59 McCoy, A. J. et al. Phaser crystallographic software. J. Appl. Crystallogr. 40, 658-674 (2007).

60 Kirsch, F. A. Phospholactic acid. FRM4118 (1966).

61 Gerlt, J. A. Genomic Enzymology: Web Tools for Leveraging Protein Family Sequence-Function Space and Genome Context to Discover Novel Functions. Biochemistry 56, 4293-4308 (2017). 
a

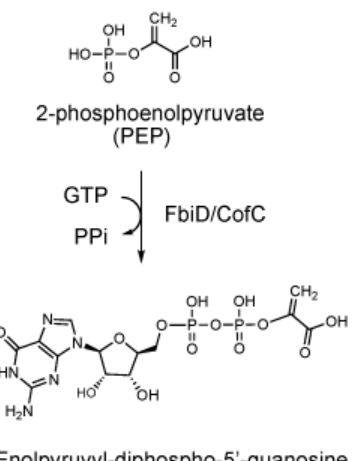

Enolpyruvyl-diphospho-5'-guanosine (EPPG)
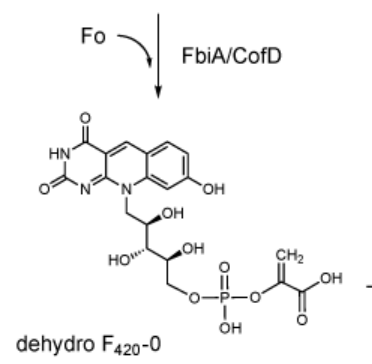
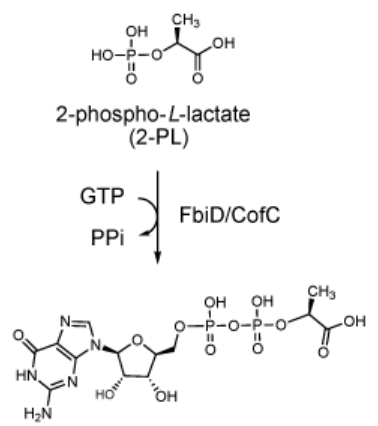

L-lactyl-2-diphospho-5'-guanosine (LPPG)

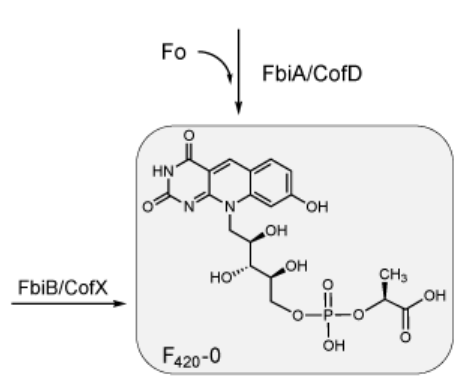

b

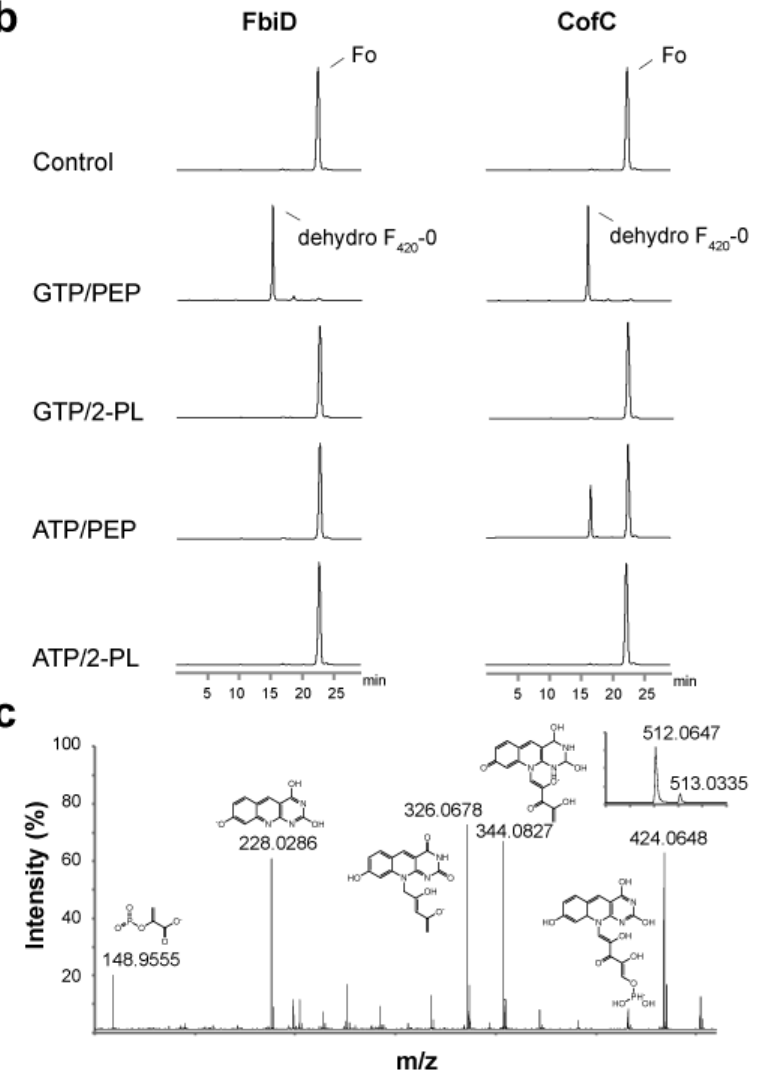

Fig. 1. Phosphoenolpyruvate (PEP) is an intermediate in the formation of dehydro-F420-

0. (a) Production of $\mathrm{F}_{420}-0$ in our revised biosynthesis pathway (left) compared to the currently accepted pathway (right). (b) Coupled-reaction HPLC assays showing that both MtbFbiD and $M j$-CofC enzymes use PEP to produce dehydro- $\mathrm{F}_{420}-0$. (c) Tandem mass spectral identification of dehydro- $\mathrm{F}_{420}-0$. MS/MS fragmentation of dehydro- $\mathrm{F}_{420}-0$, showing fragment ions with their corresponding structures. The inset displays the observed spectrum of the parent molecule (expected monoisotopic $m / z$ 512.0711 [M-H] $]^{-}$). 
a

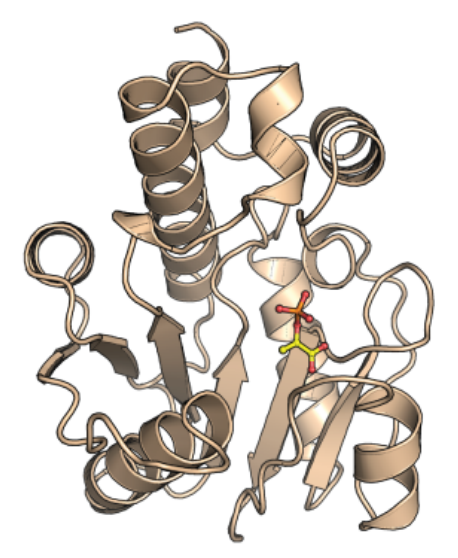

b

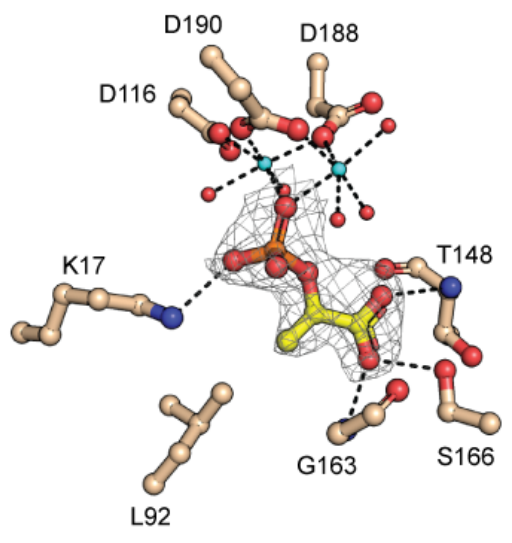

c

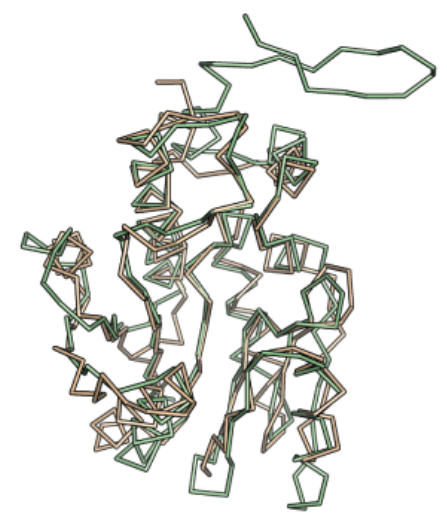

Fig. 2. Crystal structure of $M t b$-FbiD. (a) Cartoon representation of the $M t b$-FbiD structure in complex with PEP, shown as a ball-and-stick model. (b) The phosphate group of PEP binds to three aspartic acid side chains through two $\mathrm{Mg}^{2+}$ ions (shown in cyan). PEP is shown in $2 F_{\mathrm{o}}-F_{\mathrm{c}}$ omit density contoured at $2.0 \sigma$, and drawn as ball-and-stick model. Water molecules are shown as red spheres and hydrogen bond interactions are outlined as dashed lines. (c) Superposition of $M t b$-FbiD (wheat ribbon) and $M j$-CofC (green ribbon), indicating $1.85 \AA$ rmsd over 181 superimposed $\mathrm{C} \alpha$. The protruding hairpin in the $M j$-CofC structure is involved in dimer formation, which is absent in $M t b$-FbiD. 
a

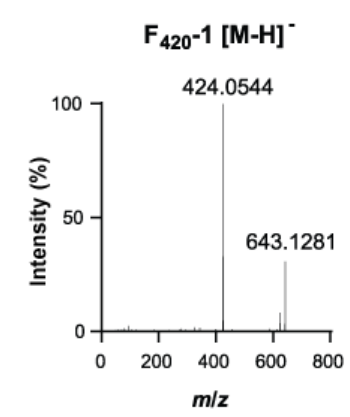

c

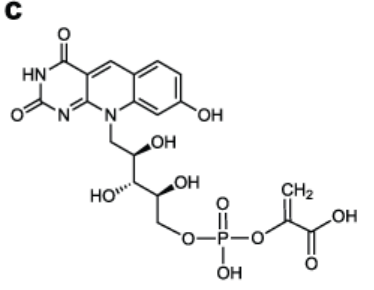

dehydro $\mathrm{F}_{420}-0$

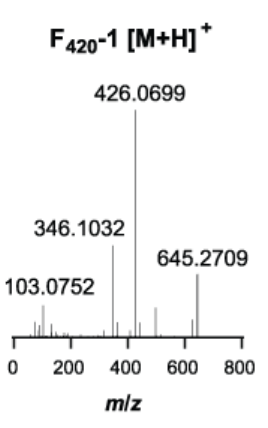

b

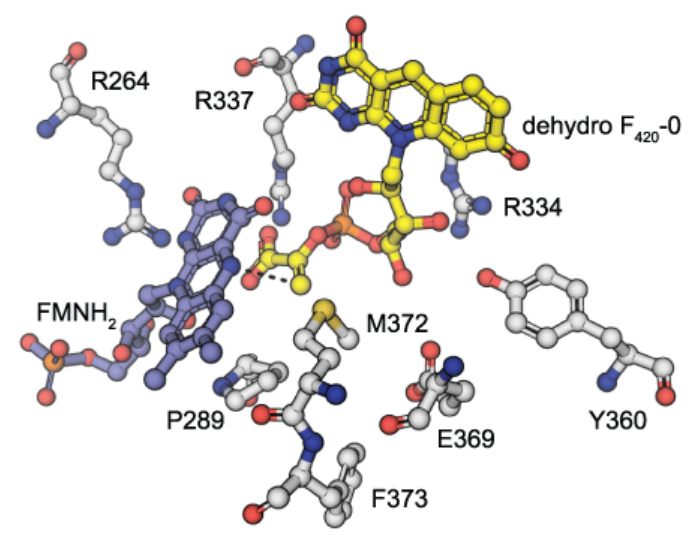

Fig. 3. $M t b$-FbiB catalyzes reduction of dehydro-F420-0. (a) $\mathrm{F}_{420}-1$ is produced in

FbiD:FbiA:FbiB coupled assays in the presence of Fre/FMNH $\mathrm{FH}_{2}$ and $L$-glutamate. MS/MS

confirmation of $\mathrm{F}_{420^{-}} 1$ in both negative (643.12811, [M-H] $\left.]^{-}\right)$and positive (645.27094,

$[\mathrm{M}+\mathrm{H}]^{+}$) modes. (b) Docking of $\mathrm{FMNH}_{2}$ and dehydro- $\mathrm{F}_{420}-0$ into the crystal structure of FbiB C-terminal domain. The methylene group of the enolpyruvyl moiety sits in a pocket made up of M372 and P289 while the carboxylate hydrogen bonds with R337. The methylene double bond sits planar above the isoalloxazine ring of $\mathrm{FMNH}_{2}$ at an appropriate distance $(3.6 \AA$, shown by dashed line) and oriented for a hydride transfer to the $S i$ face of the methylene bond, accounting for the observed (S)-lactyl moiety of $\mathrm{F}_{420}$. (c) Mtb-FbiB is a bifunctional enzyme catalyzing the reduction of dehydro- $\mathrm{F}_{420}-0$ and its poly-glutamylation to form $\mathrm{F}_{420}-\mathrm{n}$. 
a
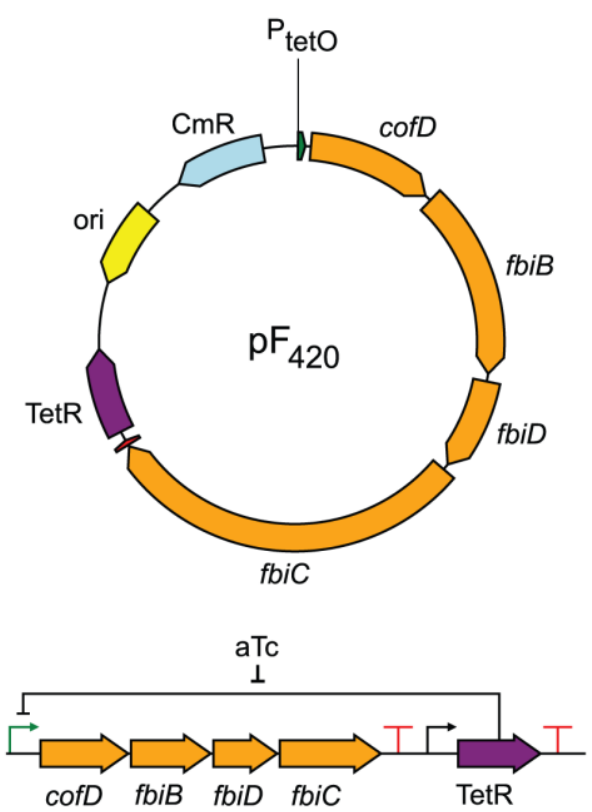

C

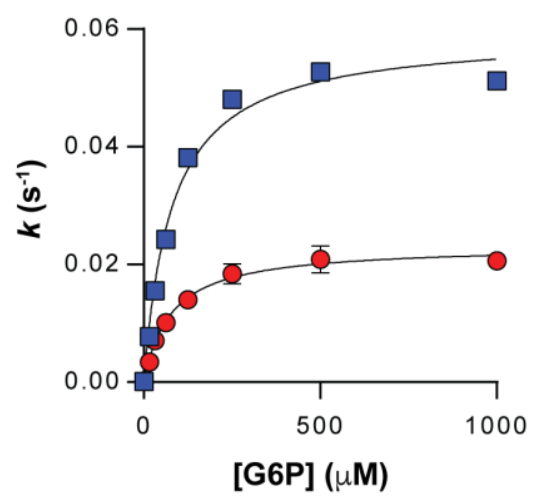

b

Standard

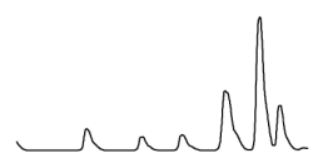

Control

Untagged

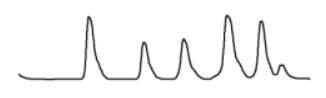

FLAG-tagged

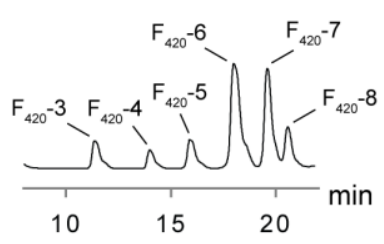

d

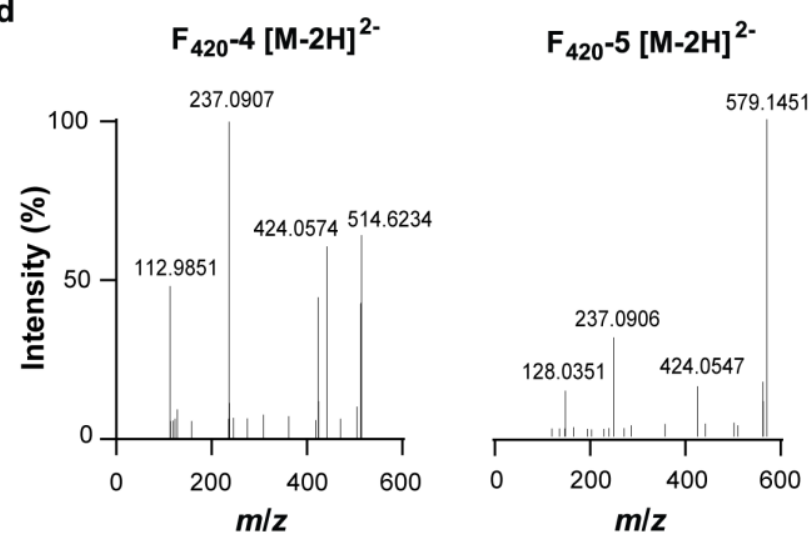

Fig. 4. Heterologous expression of $\mathrm{F}_{420}$ biosynthesis pathway in E. coli. (a) Schematic representation of the vector generated for expression of the $\mathrm{F}_{420}$ biosynthesis pathway. (b) HPLC-FLD traces of $E$. coli lysates containing $\mathrm{F}_{420}$ biosynthesis constructs as well as a purified standard from M. smegmatis. (c) Kinetic studies indicate an identical Michaelis constant for FGD as measured with $\mathrm{F}_{420}$ purified from M. smegmatis (blue) and E. coli (red). (d) Fragmentation of $\mathrm{F}_{420}-4$ and $\mathrm{F}_{420}-5$ extracted from $E$. coli shows a mature $\mathrm{F}_{420}$ production. 


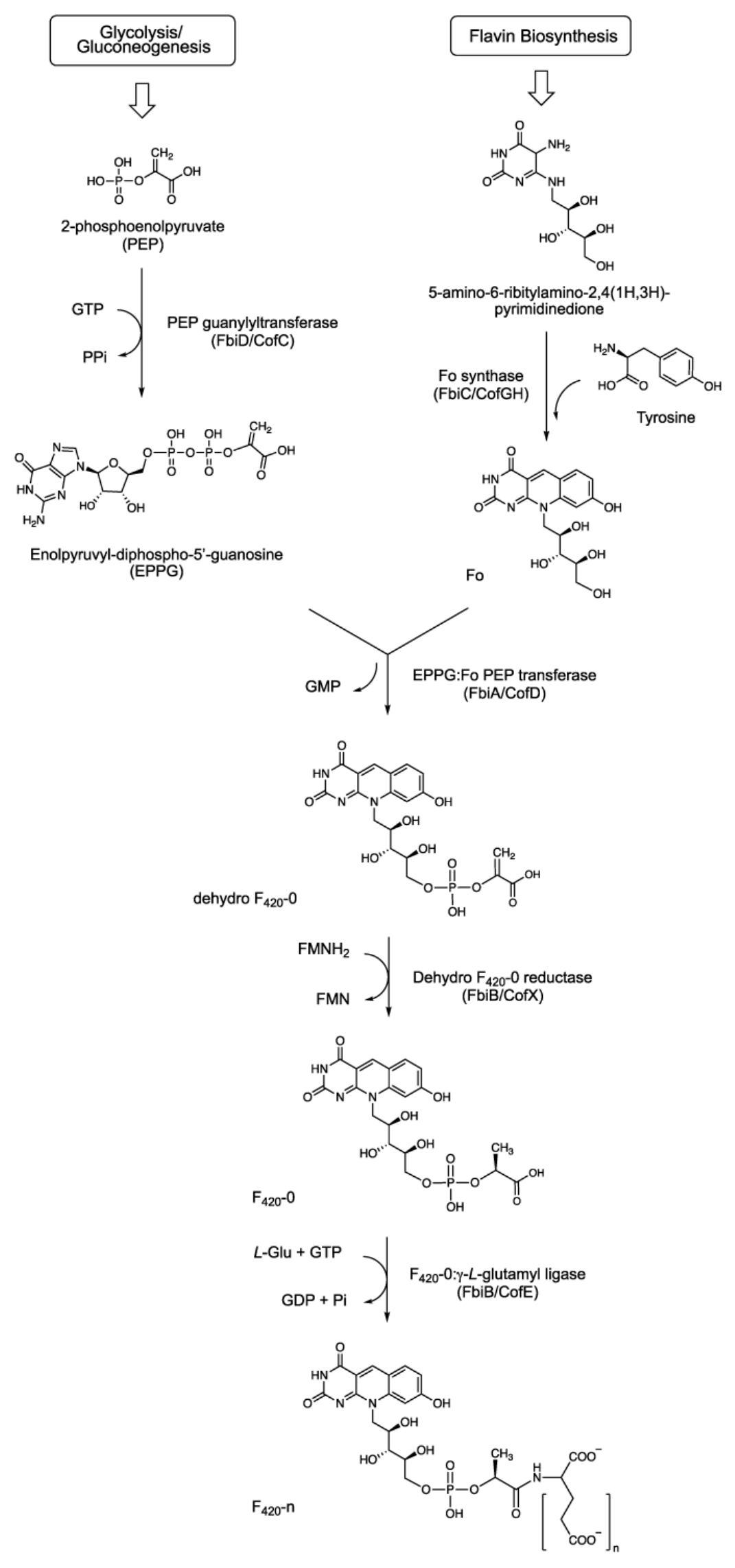


Fig. 5. The revised bacterial $\mathbf{F}_{420}$ biosynthesis pathway. The revised pathway is a modified scheme showing that PEP acts as the substrate for the FbiD/CofC enzymes to produce EPPG or EPPA (in the case of CofC). The immediate reaction product formed from Fo and EPPG/EPPA is dehydro- $\mathrm{F}_{420}-0$, which is reduced to $\mathrm{F}_{420}-0$ through the newly-described reductase activity of the $\mathrm{C}$-terminal domain of $\mathrm{FbiB}$ in mycobacteria. A separate enzyme in archaea and some bacteria is expected to catalyze this reduction step (CofX). FbiB/CofE subsequently adds a poly- $\gamma$-glutamate tail to form $\mathrm{F}_{420}$. 'Fbi' refers to bacterial proteins, whereas 'Cof' represents archaeal ones. 
a

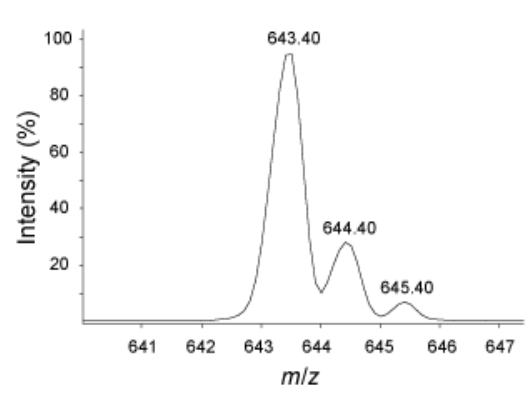

b

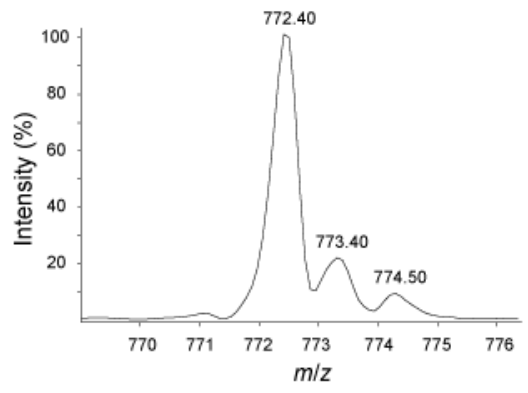

Fig. S1. Addition of $\boldsymbol{L}$-glutamate residues to dehydro-F $\mathbf{F}_{420}-\mathbf{0}$. Dehydro- $\mathrm{F}_{420}-1\left([\mathrm{M}+\mathrm{H}]^{+}\right.$, monoisotopic $m / z$ of 643.40) and dehydro- $\mathrm{F}_{420}-2\left([\mathrm{M}+\mathrm{H}]^{+}\right.$, monoisotopic $m / z$ of 772.40$)$ are formed upon the addition of one and two $L$-glutamate residues, respectively, to dehydro- $\mathrm{F}_{420}$ 0. 


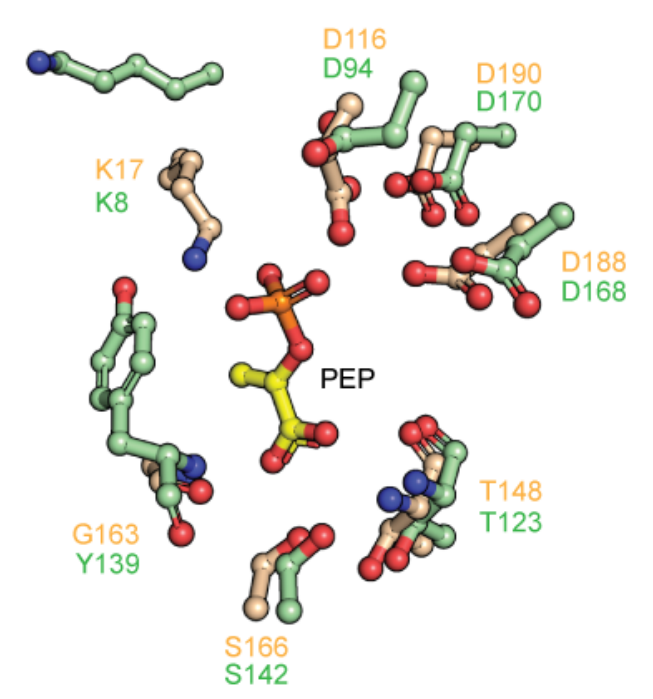

Fig. S2. Conservation of PEP binding residues between $M t b$-FbiD and $M j$-CofC.

Superposition of the $M t b-\mathrm{FbiD}$ (wheat) on to that of $M j$-CofC (green) indicates conservation of the residues in the PEP binding site of both proteins. The only change in the binding site, Gly $>$ Tyr in $M j$-CofC, is not likely to affect binding considering that the hydrogen bond interaction takes place between the backbone nitrogen atom and the oxygen atom of PEP carboxylate group. Protein side chains are shown in ball-and-stick model and labelled with the corresponding color. 


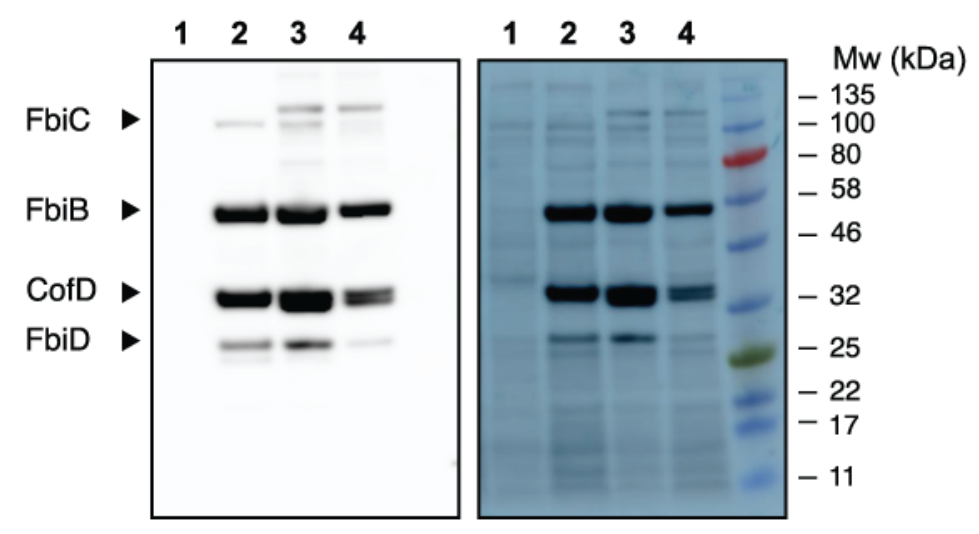

Figure S3. Expression of F420 biosynthetic genes in $\boldsymbol{E}$. coli. Whole cell lysates were resolved on SDS-PAGE, then immunoblotted with anti-FLAG antibodies to detect expression of $\mathrm{F}_{420} .1$ ) Vector-only control $28^{\circ} \mathrm{C}$; 2) $\mathrm{pF}_{420}$-FLAG expressed at $37{ }^{\circ} \mathrm{C}$; 3) $\mathrm{pF}_{420}$-FLAG expressed at $28{ }^{\circ} \mathrm{C} ; \mathrm{pF}_{420}-\mathrm{FLAG}$ expressed at $18^{\circ} \mathrm{C}$. 


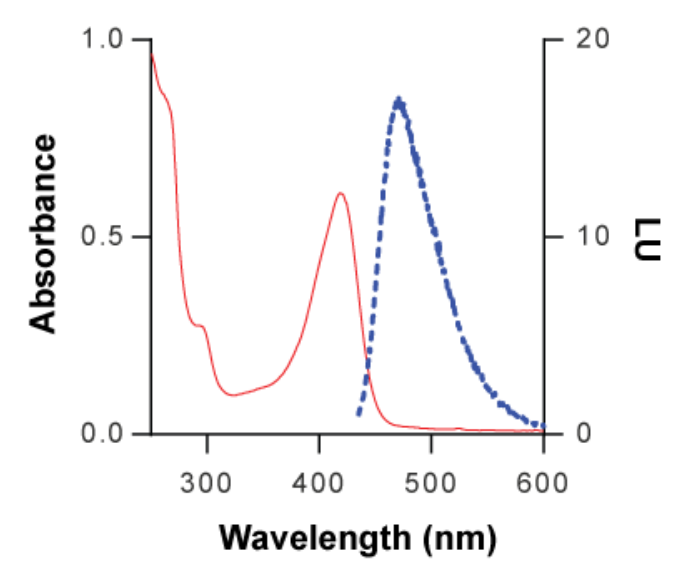

Figure S4. Spectrophotometric identification of $\boldsymbol{E}$. coli-produced F420. UV-Vis scan (red)

and fluorescence emission (blue) spectra indicate the characteristic features of $\mathrm{F}_{420}$; maximum absorption at $420 \mathrm{~nm}$ and maximum fluorescence emission at $480 \mathrm{~nm}$. 
Table S1. Primers used in the amplification of the constructs used in this study.

\begin{tabular}{l|l|l|l}
\hline \multirow{2}{*}{ Construct } & \multicolumn{2}{|l|}{ Primer Sequences $\left(\mathbf{5}^{\prime} \mathbf{- 3}^{\prime}\right)$} & $\begin{array}{l}\text { Restriction } \\
\text { site }\end{array}$ \\
\hline \multirow{2}{*}{ pYUBDuet-fbiD } & Forward & CAGGATGGATCCAGTGAGCGGCACACCGG & BamHI \\
\cline { 2 - 4 } & Reverse & GTCCCGGAAGCTTCAACGATGTGCGACCGC & HindIII \\
\hline \multirow{2}{*}{$\begin{array}{l}\text { pYUBDuet- } \\
\text { fbiAB }\end{array}$} & Forward & GAAGGAGATATACATATGAAGGTCACCGTTCTG & NdeI \\
\cline { 2 - 4 } & Reverse & GCCGGCCTTAATTAATCACTTCAGGATCAG & PacI \\
\hline \multirow{2}{*}{ pYUB28b-fbiA } & Forward & CAATGACATATGAAAGTTACCGTTCTGGC & NdeI \\
\cline { 2 - 4 } & Reverse & GCTAGTTATTGCTCAGCG & - \\
\hline \multirow{2}{*}{ pProEX-fre } & Forward & ATTAAATAAGGCGCCATGACAACCTTAAGCTG & KasI \\
\cline { 2 - 4 } & Reverse & TAATAAAAGCTTCAGATAAATGCAAACGC & HindIII \\
\hline \multirow{2}{*}{$f$ ETMCSIII- } & Forward & GTTTAATCGGATCCTAAGGAGGTTAATATTATG & - \\
\cline { 2 - 4 } & Reverse & GTTAGCAGCCGGATCTATCGATGCATGCCATGG & - \\
\hline
\end{tabular}


Table S2. Data collection, processing and refinement statistics.

\begin{tabular}{|c|c|c|c|}
\hline & SeMet-FbiD & Apo-FbiD & FbiD-PEP \\
\hline \multicolumn{4}{|l|}{ Data collection } \\
\hline Wavelength $(\AA)$ & 0.97929 & 0.95370 & 0.95370 \\
\hline Space group & $C 222_{1}$ & $C 222_{1}$ & $C 222_{1}$ \\
\hline $\begin{array}{l}\text { Cell dimensions } \\
\qquad \begin{array}{l}a(\AA) \\
b(\AA) \\
c(\AA) \\
\alpha, \beta, \gamma\left(^{\circ}\right)\end{array}\end{array}$ & $\begin{array}{l}66.56 \\
110.79 \\
167.69 \\
90,90,90\end{array}$ & $\begin{array}{l}66.54 \\
109.05 \\
166.49 \\
90,90,90\end{array}$ & $\begin{array}{l}66.17 \\
110.44 \\
165.91 \\
90,90,90\end{array}$ \\
\hline Resolution range $^{\mathrm{a}}(\AA)$ & $47.17-2.33(2.41-2.33)$ & $46.92-1.99(2.04-1.99)$ & $46.84-2.18(2.25-2.18)$ \\
\hline$R_{\text {merge }}{ }^{\mathrm{a}}$ & $0.13(0.37)$ & $0.354(2.71)$ & $0.213(2.93)$ \\
\hline$R_{\text {pim }^{\mathrm{a}}}$ & $0.035(0.1)$ & $0.095(0.757)$ & $0.057(0.827)$ \\
\hline Observed reflections ${ }^{\mathrm{a}}$ & $394201(37101)$ & $621278(38169)$ & 471504 (35875) \\
\hline Unique reflections ${ }^{\mathrm{a}}$ & $27060(2607)$ & 41955 (2818) & 32157 (2724) \\
\hline Multiplicity $^{\mathrm{a}}$ & $14.6(14.2)$ & $14.8(13.5)$ & $14.7(13.2)$ \\
\hline Mean $\mathrm{I} / \sigma \mathrm{I}^{\mathrm{a}}$ & $21.3(8.1)$ & $8.8(1.2)$ & $14.5(1.0)$ \\
\hline Completeness $(\%)^{\mathrm{a}}$ & $99.91(99.3)$ & 99.85 (96.9) & $100.0(99.7)$ \\
\hline $\mathrm{CC}(1 / 2)^{\mathrm{b}}$ & $0.995(0.97)$ & $0.994(0.321)$ & $0.998(0.376)$ \\
\hline $\mathrm{R}_{\text {Cullis }}$ anomalous & 0.95 & & \\
\hline $\operatorname{MapCC}^{\mathrm{c}}(\%)$ & 71.25 & & \\
\hline Mean FOM & 0.697 & & \\
\hline \multicolumn{4}{|l|}{ Refinement } \\
\hline PDB code & & $6 \mathrm{BWG}$ & $6 \mathrm{BWH}$ \\
\hline Resolution range ( $\AA$ ) & & $83.25-1.99$ & $82.95-2.18$ \\
\hline$R_{\text {work }} / R_{\text {free }}(\%)$ & & $19.1 / 22.8$ & $22.8 / 26.2$ \\
\hline $\begin{array}{l}\text { Number of atoms (non- } \\
\text { hydrogen) }\end{array}$ & & & \\
\hline Protein & & 4969 & 4643 \\
\hline Ligand & & - & 36 \\
\hline Solvent & & 544 & 180 \\
\hline R.m.s.d. from ideality & & & \\
\hline Bonds $(\AA)$ & & 0.011 & 0.01 \\
\hline Angles $\left({ }^{\circ}\right)$ & & 1.416 & 1.383 \\
\hline Average $B$ factors $\left(\AA^{2}\right)$ & & & \\
\hline Protein & & 11.98 & 24.12 \\
\hline $\operatorname{PEP}(n=3)$ & & - & 48.78 \\
\hline $\mathrm{Mg}^{2+}(\mathrm{n}=6)$ & & - & 44.33 \\
\hline Waters & & 33.18 & 48.46 \\
\hline $\begin{array}{l}\text { Ramachandran } \\
\text { statistics }\end{array}$ & & & \\
\hline Favored (\%) & & 99.18 & 99.02 \\
\hline Allowed (\%) & & 0.82 & 0.98 \\
\hline Outliers $(\%)$ & & 00 & 00 \\
\hline $\begin{array}{l}\text { Molprobity score/ } \\
\text { percentile }\end{array}$ & & $1.07 / 100^{\text {th }}$ & $1.35 / 99^{\text {th }}$ \\
\hline
\end{tabular}

${ }^{a}$ Values in parentheses are for the outermost resolution shell.

${ }^{\mathrm{b}}$ Pearson correlation coefficient.

${ }^{\mathrm{c}}$ Map correlation coefficient. 

not certified by peer review) is the author/funder. All rights reserved. No reuse allowed without permission.

Table S3. Kinetic parameters of FGD with $\mathrm{F}_{420}$ purified from M. smegmatis and E. coli.

\begin{tabular}{lcc}
\hline & $k_{\mathrm{cat}(\mathrm{app})}\left(\mathrm{s}^{-1}\right)$ & $K_{\mathrm{m}(\mathrm{app})}(\mu \mathrm{M})$ \\
\hline M. smegmatis & $1.19 \pm 0.05$ & $79 \pm 11$ \\
E. coli & $0.46 \pm 0.02$ & $77 \pm 7$ \\
\hline
\end{tabular}

